\title{
The Arabidopsis AtNPR1 Inversely Modulates Defense Responses Against Fungal, Bacterial, or Viral Pathogens While Conferring Hypersensitivity to Abiotic Stresses in Transgenic Rice
}

\author{
Jordi Quilis, ${ }^{1,2}$ Gisela Peñas, ${ }^{1,3}$ Joaquima Messeguer ${ }^{3}$ Christophe Brugidou, ${ }^{4}$ and Blanca San Segundo ${ }^{1,2}$ \\ ${ }^{1}$ Consorcio CSIC-IRTA Laboratorio de Genética Molecular Vegetal, Jordi Girona 18, 08034 Barcelona, Spain; ${ }^{2}$ Departamento \\ de Genética Molecular, ${ }^{3}$ Departamento de Genética Vegetal, and ${ }^{4}$ Institut de Recherche pour le Développement, UMR 5096 \\ (CNRS-IRD-UP), Montpellier, France
}

Submitted 14 January 2008. Accepted 27 April 2008.

\begin{abstract}
The nonexpressor of pathogenesis-related $(P R)$ genes (NPR1) protein plays an important role in mediating defense responses activated by pathogens in Arabidopsis. In rice, a disease-resistance pathway similar to the Arabidopsis NPR1mediated signaling pathway one has been described. Here, we show that constitutive expression of the Arabidopsis NPRI (AtNPR1) gene in rice confers resistance against fungal and bacterial pathogens. AtNPRI exerts its protective effects against fungal pathogens by priming the expression of salicylic acid (SA)-responsive endogenous genes, such as the PRIb, TLP (PR5), PR10, and PBZ1. However, expression of AtNPR1 in rice has negative effects on viral infections. The AtNPRI-expressing rice plants showed a higher susceptibility to infection by the Rice yellow mottle virus (RYMV) which correlated well with a misregulation of RYMV-responsive genes, including expression of the SA-regulated RNA-dependent RNA polymerase 1 gene $(O S R D R 1)$. Moreover, AtNPRI negatively regulates the expression of genes playing a role in the plant response to salt and drought stress (rab21, salT, and dip1), which results in a higher sensitivity of AtNPRI rice to the two types of abiotic stress. These observations suggest that $A t N P R 1$ has both positive and negative regulatory roles in mediating defense responses against biotic and abiotic stresses.
\end{abstract}

Additional keywords: Erwinia chrysanthemi, Fusarium verticillioides, Magnaporthe oryzae, and Oryza sativa.

Plant signaling pathways involved in the plant response to biotic and abiotic stresses are composed of intricate networks with frequent cross-talk that allow the plant to activate an appropriate spectrum of responses depending on the nature of the external stimuli. This leads to the production of proteins with direct roles in alleviating the damaging effects of stressful conditions. The plant response to pathogen attack includes the rapid generation of reactive oxygen species, changes in ion fluxes across the plasma membrane, cell wall reinforcement, activation of protein phosphorylation or dephosphorylation

Corresponding author: B. San Segundo; Telephone: 349340061 28; Fax: 349320459 04; E-mail: bssgmb@cid.csic.es

* The $\boldsymbol{e}$-Xtra logo stands for "electronic extra" and indicates that Figures 2, 3, 4, 7, and 10 appear in color online. cascades, production of antimicrobial compounds (i.e., phytoalexins), and accumulation of pathogenesis-related (PR) proteins (Hammond-Kosack and Parker 2003; van Loon et al. 2006). Moreover, resistance responses locally activated in primary pathogen-infected plant tissues are often extended to distant, noninfected tissues, a phenomenon which is referred to as systemic acquired resistance (SAR) (Ryals et al. 1996). Establishment of SAR is associated with the coordinated expression of SAR genes, many of these encoding PR proteins (Ward et al. 1991), as well as with the induction of the protein secretory pathway (Wang et al. 2005). In Arabidopsis and tobacco plants, salicylic acid (SA) is an essential signal molecule for SAR (Dempsey et al. 1999).

The nonexpressor of $P R$ genes (NPRl) (also known as niml, noninducible immunity) gene is a key regulator of SA-mediated SAR in Arabidopsis (Cao et al. 1994, 1997; Delaney et al. 1995; Glazebrook et al. 1996; Ryals et al. 1997; Shah et al. 1997). NPR1 regulates expression of Arabidopsis defense genes by interacting with members of the TGA class of basic, leucine-zipper transcription factors (Despres et al. 2000; Zhang et al. 1999; Zhou et al. 2000). Redox changes in Arabidopsis cells regulate the functioning of NPR1 (Mou et al. 2003). In noninduced cells, oxidized NPR1 forms inactive oligomers that remain in the cytosol. SA application or exposure of the plant to the pathogen triggers a change in the molecular stage of NPR1, the NPR1 protein being reduced from an inactive oligomeric complex to an active monomeric state. Monomeric NPR1 is then translocated into the nucleus where it interacts with TGA factors for activation of $P R$ gene expression (Despres et al. 2000; Kinkema et al. 2000; Rochon et al. 2006; Zhang et al. 2003).

It is also known that overexpression of the Arabidopsis NPRI (hereafter referred to as AtNPRl) gene in Arabidopsis results in enhanced resistance to bacterial and oomycete pathogens (Cao et al. 1998; Friedrich et al. 2001). When introduced into rice, AtNPRl confers resistance to the bacterial pathogen Xanthomonas oryzae pv. oryzae (Chern et al. 2001; Fitzgerald et al. 2004). Overexpression of the rice AtNPRl homolog, the OsNPRl gene (also named NHI), also enhances plant resistance to X. oryzae pv. oryzae in rice (Chern et al. 2005; Yuan et al. 2007). Together, these findings support the existence of a disease resistance pathway in rice similar to the Arabidopsis NPRl-mediated signaling pathway. Moreover, wheat and tomato plants expressing the Arabidopsis AtNPRl gene displayed enhanced resistance to fungal and bacterial diseases (Lin et al. 
2004; Makandar et al. 2006). More recently, overexpression of an AtNPR1 homolog from apple (MpNPR1-1) in transgenic apple has been shown to confer increased resistance to a bacterial and two fungal pathogens (Malnoy et al. 2007). In other studies, overexpression of $O S N P R 1$ in rice results in enhanced herbivore susceptibility (Yuan et al. 2007). No information is currently available on the possible involvement of AtNPRl as a regulator of plant responses to abiotic stresses.

On the other hand, contradictory results are found in the literature on the possible involvement of AtNPRl in plant-virus interactions. Whereas AtNPRl appears not to be required for resistance to Turnip crinkle virus in Arabidopsis plants (Kachroo et al. 2000), the tobacco NPRl gene appears to be required for $\mathrm{N}$-mediated resistance to Tobacco mosaic virus (TMV) (Liu et al. 2002). Concerning the plant response to viral infection, it is well known that RNA-dependent RNA polymerases (RDR or $\mathrm{RdRP}$ ) are implicated in antiviral defenses. Plant RDR also participate in post-transcriptional gene silencing (PTGS) (Baulcombe 2004; Dalmay et al. 2000; Mourrain et al. 2000). Three functional RDR (RDR1, RDR2, and RDR6) have been identified in plants (Wassenegger and Krczal 2006). In Arabidopsis, RDR1 and RDR6 (also known as SDE1 and SGS2) are required in the cytoplasmatic RNA silencing pathway that silences transgenes and viruses. Moreover, the expression of the Arabidopsis and tobacco RDRl genes (referred as AtRdRP1, $N t R d R P 1$, and $N b R d R P 1$ ) has been described to be induced by treatment with SA and infection with certain viruses (Xie et al. 2001; Yang et al. 2004; Yu et al. 2003).

In this work, we generated transgenic rice lines constitutively expressing the Arabidopsis AtNPRl gene. The impact of transgenic expression of AtNPRl on the expression of stressrelated rice genes as well as performance of AtNPRI rice plants grown under stress conditions, both biotic and abiotic conditions, was determined. We show that AtNPR1 modulates the expression of genes involved in resistance to different types of fungal, bacterial, or viral pathogens. Whereas expression of AtNPR1 in rice confers resistance to fungal and bacterial pathogens, AtNPRI rice shows higher susceptibility to infection by the Rice yellow mottle virus (RYMV). Finally, the expression of AtNPRl in rice notably interferes with the expression of salt and drought-associated genes, which results in hypersensitivity to these two types of abiotic stresses.

\section{RESULTS}

\section{Phenotype of AtNPR1 rice plants.}

For expression of the Arabidopsis AtNPRl gene in transgenic rice, a pCAMBIA-derived construct containing the AtNPRI cDNA (Cao et al. 1997) under the control of the maize ubiquitin-1 (ubi) promoter was prepared. The elite japonica rice (Oryza sativa L.) cultivar was used in this study. Transgenic rice was produced by Agrobacterium-mediated transformation. Representative T0 events accumulating AtNPR1 $m R N A$ at different levels in their leaves were selected (Fig. 1A) and used as the parental lines to obtain T2 homozygous progeny plants. Northern blot analysis of selected AtNPRI rice plants confirmed stable expression and inheritance of the transgene for at least three generations (results not shown).

The developmental performance of AtNPR1 rice plants grown in the greenhouse differed from that of control, nontransformed plants. Thus, transgenic AtNPRl rice plants grown in the greenhouse showed growth retardation and reduced height compared with wild-type plants (Fig. 1B). Moreover, seeds produced by AtNPRI plants were smaller than seeds produced by control plants (Fig. 1C). Other studies in Arabidopsis showed the effects caused by an alteration in the level of AtNPRl expression, or mutations that either prevent (nprl mutant) or cause a constitu- tive expression (cpr mutants) of the inducible plant defense response on plant fitness (Heidel and Dong 2006; Heidel et al. 2004). These studies revealed that the precise fitness consequences of these mutations and transgenics were highly dependent on the environmental context. Although results here presented show that AtNPRl expression in rice has important consequences in terms of the "physiological costs" of the plant when growing under controlled conditions, an interpretation for these results in terms of the balance between fitness costs and disease resistance will require additional studies in plants growing under different environmental conditions.

When transferred to plant growth chambers, AtNPRl plants developed spontaneous lesions in their leaves evoking a lesion mimic phenotype (Fig. 2A). Lesions were visible as early as 2 to 3 days after transferring these plants from the greenhouse to the growth chamber. Transgenic AtNPRl rice lines maintained in the greenhouse did not exhibit lesions. The typical cellular markers of lesion formation, such as accumulation of superoxide $\left(\mathrm{O}_{2}^{-}\right)$ions and autofluorescent material in the cell walls, were also produced in AtNPRl plants grown in the growth chamber (Fig. 2B and C). None of these histochemical markers (accumulation of superoxide and autofluorescent material) were detected in greenhouse-grown AtNPRI plants (data not shown). Together, these studies revealed that constitutive expression of AtNPR1 in rice reduces growth and productivity in the greenhouse and, only in growth chambers, AtNPRl triggers development of spontaneous lesions. These results contrast with those obtained in Arabidopsis plants which exhibited no visible phenotypic alterations despite constitutive expression of the AtNPRl gene (Cao et al. 1998).

\section{Disease resistance of $A t N P R 1$ rice plants to fungal and bacterial pathogens.}

Transgenic AtNPR1 plants were tested for resistance to infection with the fungal pathogens Magnaporthe oryzae and Fusarium verticillioides, the causal agents of the blast and bakanae diseases of rice. Four independently derived T2 homozygous lines were used in all the disease resistance assays carried out in this work (lines 1,2,13, and 24). For studies on blast resistance, leaves from AtNPRl and wild-type plants were inoculated with increasing doses of $M$. oryzae spores. Differences in the degree and development of disease symptoms caused by $M$. oryzae between AtNPRI and untransformed plants were clearly observed (Fig. 3A). Blast lesions developed actively in leaves of wild-type plants but not in leaves of AtNPRI lines. The ability of AtNPRI plants to block the in planta growth of $M$. oryzae was further assessed by measuring the average lesion size and by counting the number of spores produced in infected leaves of both control and transgenic lines (Fig. 3B and C).

Resistance of AtNPRl rice seedlings against the fungus $F$. verticillioides, a seedborne and soil-transmitted pathogen, was assayed. F. verticillioides-infected seed from the AtNPRI lines germinated and developed (Fig. 3D). In contrast, fungusinfected seed from wild-type plants showed pathogen colonization and did not germinate.

Finally, we determined whether AtNPRl lines exhibit resistance to Erwinia chrysanthemi, a bacterial pathogen that causes the foot rot disease of rice (Goto 1979). Ten days after infection, nontransformed seedlings showed typical symptoms of $E$. chrysanthemi infection, the roots becoming decayed and easily pulling off (Fig. 4, upper panels). Transgenic lines consistently performed better than controls, developed roots normally, and grew more vigorously (Fig. 4, lower panels). We further tested the effect of E. chrysanthemi infection on wild-type and transgenic lines by determining the length of inoculated roots relative to that of noninoculated roots for each line (in each case, 
an arbitrary value of 1 was given to roots of noninfected seedlings). At 6 days after inoculation, the relative growth of infected roots from wild-type seedlings compared with noninfected roots was 0.27 , whereas the relative growth for each transgenic line (inoculated versus noninoculated plants) was 0.80 for line 1, 0.70 for line 13, and 0.94 for line 24 (data are the means \pm standard error of 60 plants). Together, disease resistance assays demonstrated that expression of AtNPRI in rice confers resistance to fungal and bacterial pathogens.

\section{Priming for enhanced responses}

\section{to fungal infection in AtNPR1 rice plants.}

The expression and pattern of fungal induction of the endogenous defense genes was examined in AtNPRI plants and com- pared with that of wild-type plants. For this, total RNA was isolated from leaves of control and AtNPRI lines at different times after inoculation with $M$. oryzae spores. Total RNAs were then used for reverse-transcriptase polymerase chain reaction (RT-PCR) experiments using gene-specific primers for the OSPRIb, probenazole-inducible $1(P B Z 1), O S P R 10$, and PR5 (thaumatin-like protein $[T L P]$ ) genes. These genes have been identified as defense markers of the rice response to pathogen infection (Agrawal et al. 2001; Midoh and Iwata 1996; Velazhahan et al. 1998). None of these genes was expressed in the absence of the pathogen in either wild-type or transgenic plants (Fig. 5A). In fungus-infected AtNPRl plants, transcripts for all four rice defense genes accumulated earlier and at higher levels than in fungus-infected wild-type plants
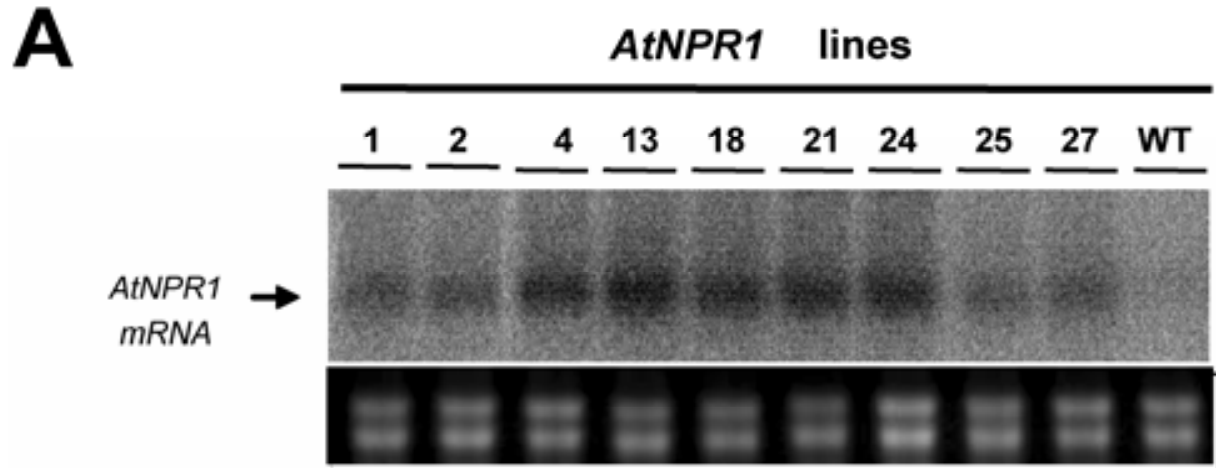

B

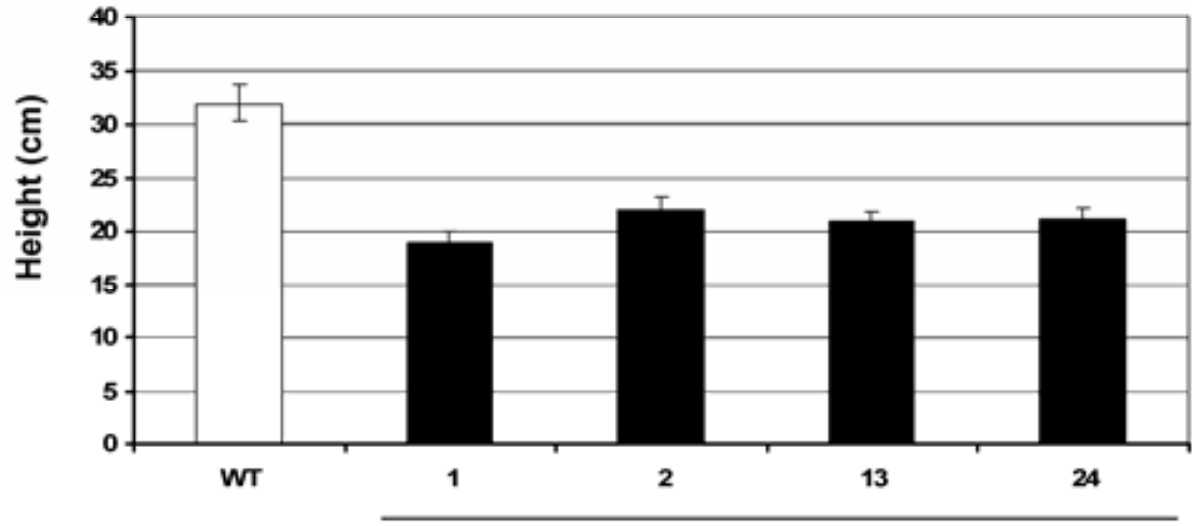

AtNPR1 lines
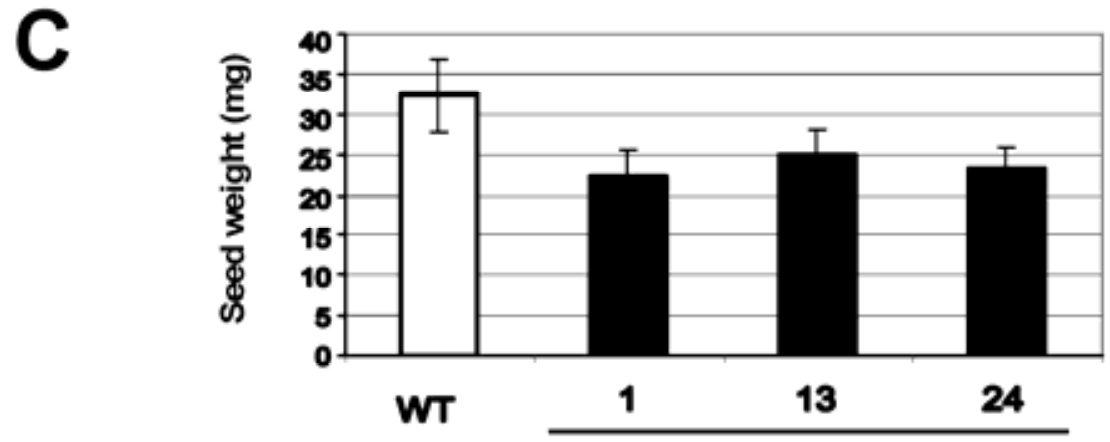

AtNPR1 lines

Fig. 1. Expression of AtNPR1 in rice plants. A, Northern blot analysis of transgenic rice plants (T0 generation). Total RNAs (10 $\mu \mathrm{g})$ were subjected to formaldehyde-containing agarose gel electrophoresis and hybridized with a ${ }^{32} \mathrm{P}$-labeled cDNA probe. Lane WT, untransformed Senia control. Lower panels show ethidium bromide staining of RNA samples. B, Mean height of AtNPR1 rice plants (T2 homozygous lines) compared with WT plants. Four independently generated AtNPR1 lines (lines 1,2,13, and 24) and WT plants were grown in the greenhouse under control conditions for 3 weeks. Means were calculated from four independent transgenic lines with 48 plants for each line, and two repeats. The data represent mean and standard error $(P<0.05)$. C, Weight of seed produced by AtNPRI and WT rice plants. Seed were collected from transgenic and wild-type plants and pooled (48 plants per line); 200 seeds from each pool were weighted and the mean weight per seed was calculated. The data represent the mean weight and standard error $(P<0.05)$. 

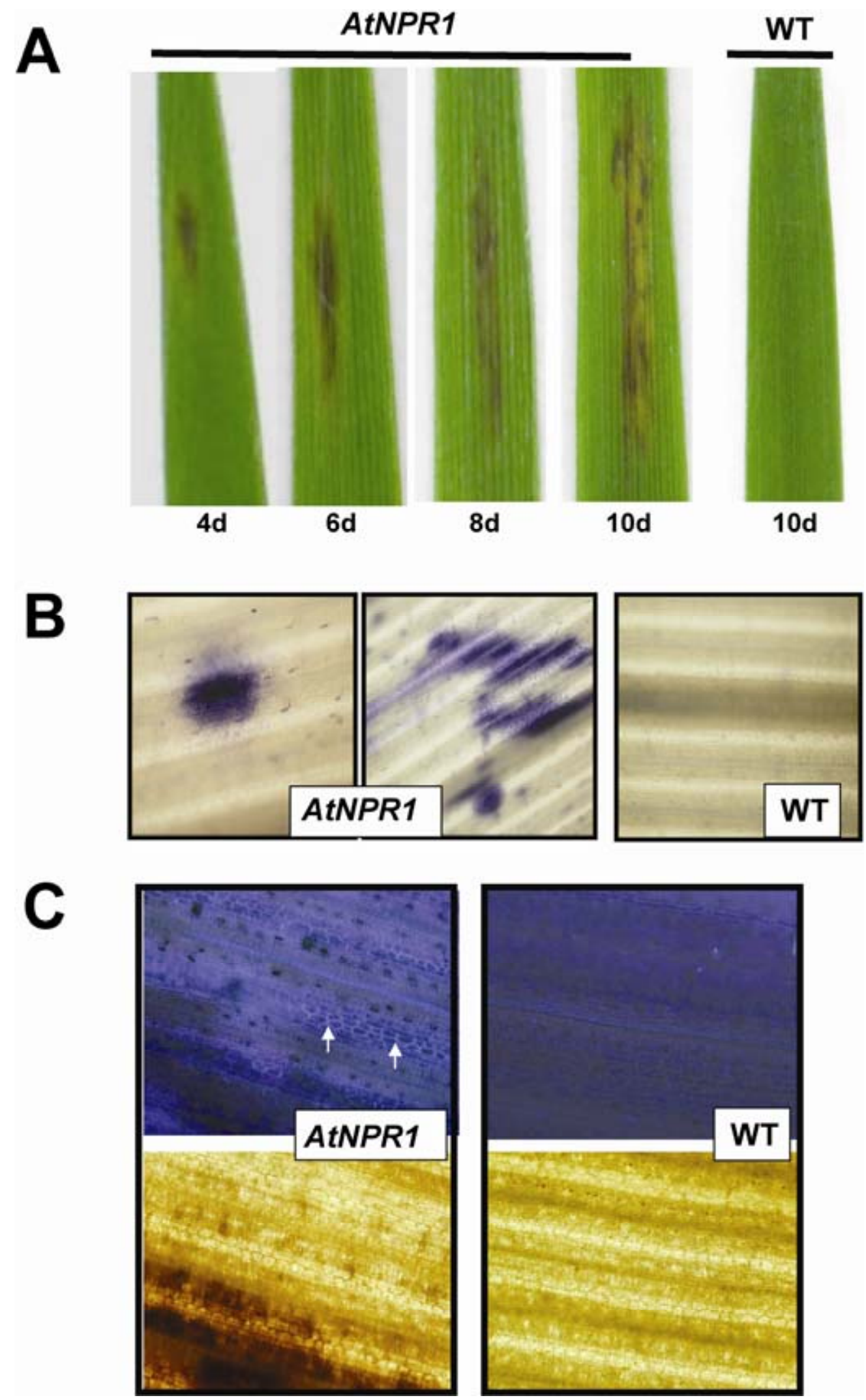

Fig. 2. Development of spontaneous lesions and expression of histochemical markers in the AtNPR1 plants grown under growth-chamber conditions. A, Plants were grown in the greenhouse for 3 weeks and then transferred to the growth chamber. Lesion phenotype of AtNPRI plants at 4, 6, 8 and 10 days are shown. Leaves of wild-type (WT) plants grown in the growth chamber for 10 days did not develop lesions. B, Histochemical detection of superoxide in AtNPR1 plants grown for 3 days in the growth chamber. Leaves were stained with nitro blue tetrazolium (NBT). Reduction of NBT to formazan yields a bluish precipitate in the presence of $\mathrm{O}_{2}^{-}$. C, Detection of autofluorescent material in AtNPR1 plants grown under growth-chamber conditions. Leaves were viewed by fluorescence (upper panels) or bright-field (lower panels) microscopy from the top side. Autofluorescent material accumulated in the cell walls in the leaves of transgenic lines (arrows) but not in leaves of WT plants. 
A

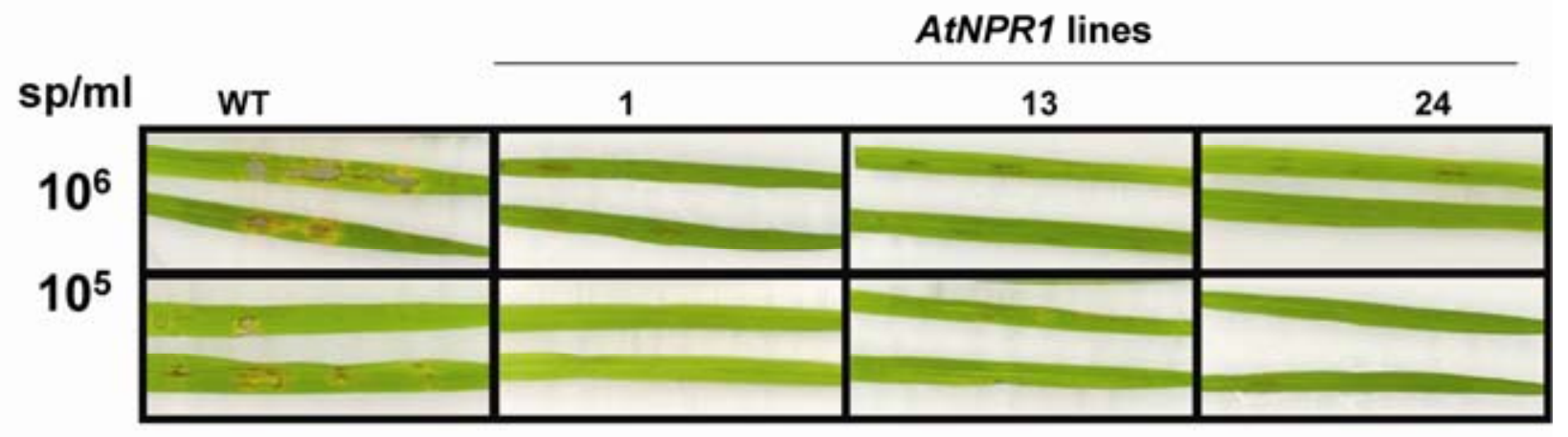

B
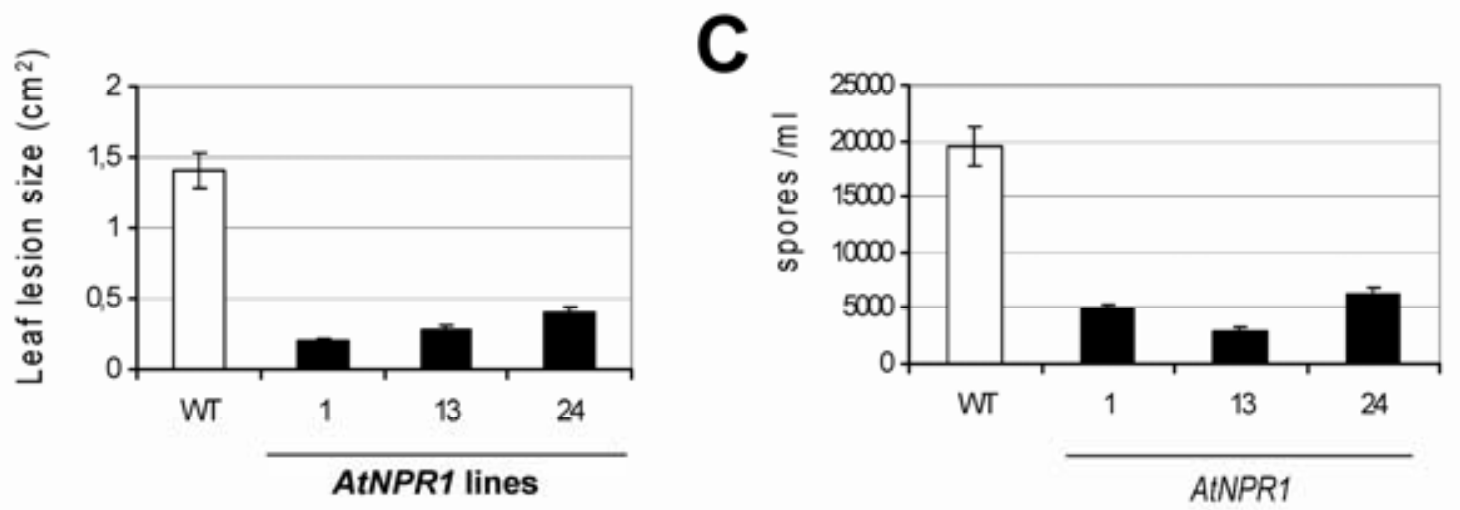

D
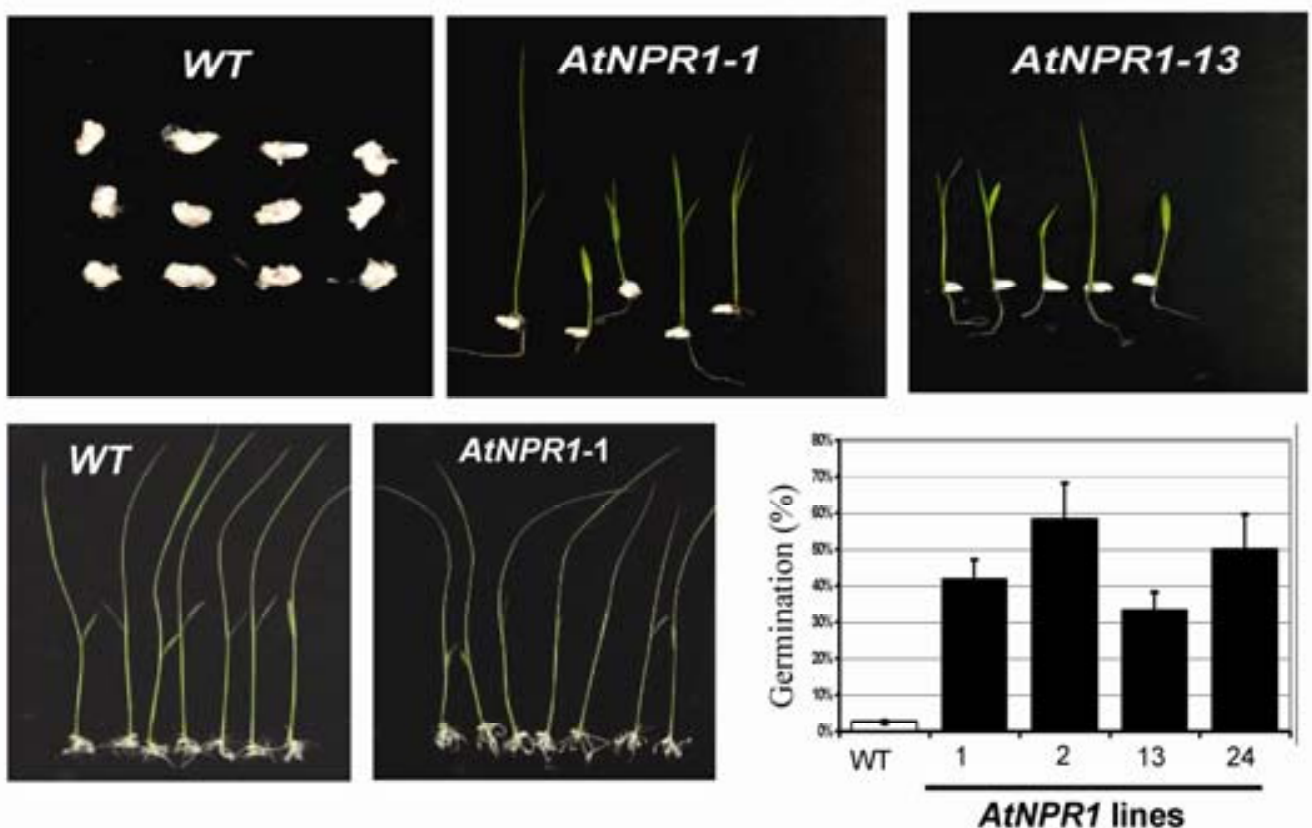

Fig. 3. Resistance of rice plants expressing the AtNPR1 gene to infection by the fungal pathogens A through $\mathbf{C}$, Magnaporthe oryzae and $\mathbf{D}$, Fusarium verticillioides. Similar results were observed with the four independent AtNPR1 lines under study (lines 1,2, 13, and 24). A, Resistance to infection by M. oryzae. Leaves from control untransformed Senia plants (WT) and AtNPR1 rice lines were locally inoculated with M. oryzae spores. The concentration of inoculum is indicated on the left. Disease symptoms 3 days after inoculation of leaves are shown. Results shown are from one of four experiments, that produced similar results. B, Size of lesions $\left(\mathrm{cm}^{2}\right)$ produced on the leaves of the control and AtNPRl rice lines 6 days after inoculation with M. oryzae spores. For inoculation, $20 \mu \mathrm{l}$ of a spore suspension at $1 \times 10^{6}$ spores $/ \mathrm{ml}$ was used. The average lesion area was determined from spot infections (three inoculations per leaf, three leaves per plant, and three plants per line). Error bars represent standard deviation (SD). C, Counting of spores produced in M. oryzae-infected leaves at 6 days after inoculation. Values given represent the mean and standard error for three countings for each infected leaf and three leaves for each transgenic line. D, Resistance to infection by F. verticillioides. Seed were germinated for $24 \mathrm{~h}$, inoculated with $50 \mu \mathrm{l}$ of fungal spores (10 spores $/ \mathrm{ml}$ ) (upper panels) or with sterile water (lower panels), and then allowed to continue germination. Picture was taken at 9 days after inoculation with fungal spores. Pictures shown are from one of four experiments that gave similar results. The percentage of seed that germinated under infection conditions relative to noninfected seeds was scored for each line at 6 days after inoculation with fungal spores (the histogram shows the means \pm SD of four independent experiments). 
(Fig. 5A). The four independently generated AtNPRl rice lines studied in this work (lines 1,2,13, and 24) showed faster and stronger activation of the $O S P R I b, P B Z 1, T L P$, and $O S P R 10$ genes, supporting the idea that AtNPRl plants exhibit an enhanced capacity to activate the natural plant defense mechanisms, a phenomenon known as "priming" (Conrath et al. 2006).

Next, the response of the rice defense genes under study to treatment with SA was investigated. Treatment with SA strongly induces the expression of the OSPRIb, TLP, OsPR10, and PBZ1 genes in both wild-type and transgenic rice plants (Fig. 5B). These results suggest that, under infection conditions, the expression of AtNPRI in rice primes for enhanced responses of endogenous genes which also show SA responsiveness in rice.

Finally, we investigated whether development of spontaneous lesions in transgenic plants grown under growth-chamber conditions was accompanied by the expression of defenserelated genes in AtNPRl plants. For this, wild-type and transgenic lines were grown for 2 weeks in the greenhouse and transferred to the growth chamber for 3 days. By this time, expression of the PRIb, PBZ1, TLP (PR5), and OsPRIO genes was found to be activated in leaves of AtNPRI plants but not in leaves of wild-type plants, which were maintained under the same growing conditions (Fig. 5C).

\section{AtNPR1 rice plants show altered expression of RYMV-responsive genes.}

In this work, we also examined the expression of rice genes whose expression is associated to the rice response to viral infections. Previous proteomic studies by Ventelon-Debout and associates (2004) indicated that infection by RYMV results in alterations in the level of accumulation of a large number of rice proteins, including PR10A (accession number Q9LKJ9), the translation initiation factor 5A (tIF5A, accession number Q9ZSU2), and a salt-stress-induced protein (accession number $\mathrm{P} 24120)$. PR10A is a member of the PR10 family of rice PR proteins which is different from that showing fungal responsiveness in rice plants (Fig. 5A). In this work, total RNA was extracted from locally inoculated ( 7 days postinoculation [dpi]), and mock-inoculated leaves of AtNPR1 and wild-type plants and used for expression studies. In the absence of RYMV infection, no expression was observed for any of the rice genes under study (tIF5A, salt-stress induced protein, and OsPR10A) in either wild-type or transgenic plants (Fig. 6A). Upon infection of wild-type plants with RYMV, induction of tIF5A and salt-stress-induced protein gene expression, but not OsPR10A expression, occurred in wild-type plants. An opposite response to RYMV infection was observed in AtNPRl plants. In this case, OSPR10A expression but not $t I F 5 A$ and salt-stress-induced protein expression was induced by RYMV infection. Thus, this study revealed that transgenic expression of AtNPRI results in altered expression of RYMV-responsive rice genes, at least of the OsPRIOA, tIF5A, and salt-stressinduced protein rice genes. We also investigated the expression of the $I I F 5 A$ and OSPR1OA genes in two reference rice cultivars, Gigante and IR64 (highly resistant and highly susceptible to RYMV infection, respectively) (discussed below). This study revealed a similar response to RYMV infection in AtNPRl and IR64 plants (i.e., viral infection induced $O S P R 10$ but not $t I F 5 A$

\section{E. chrysanthemi}
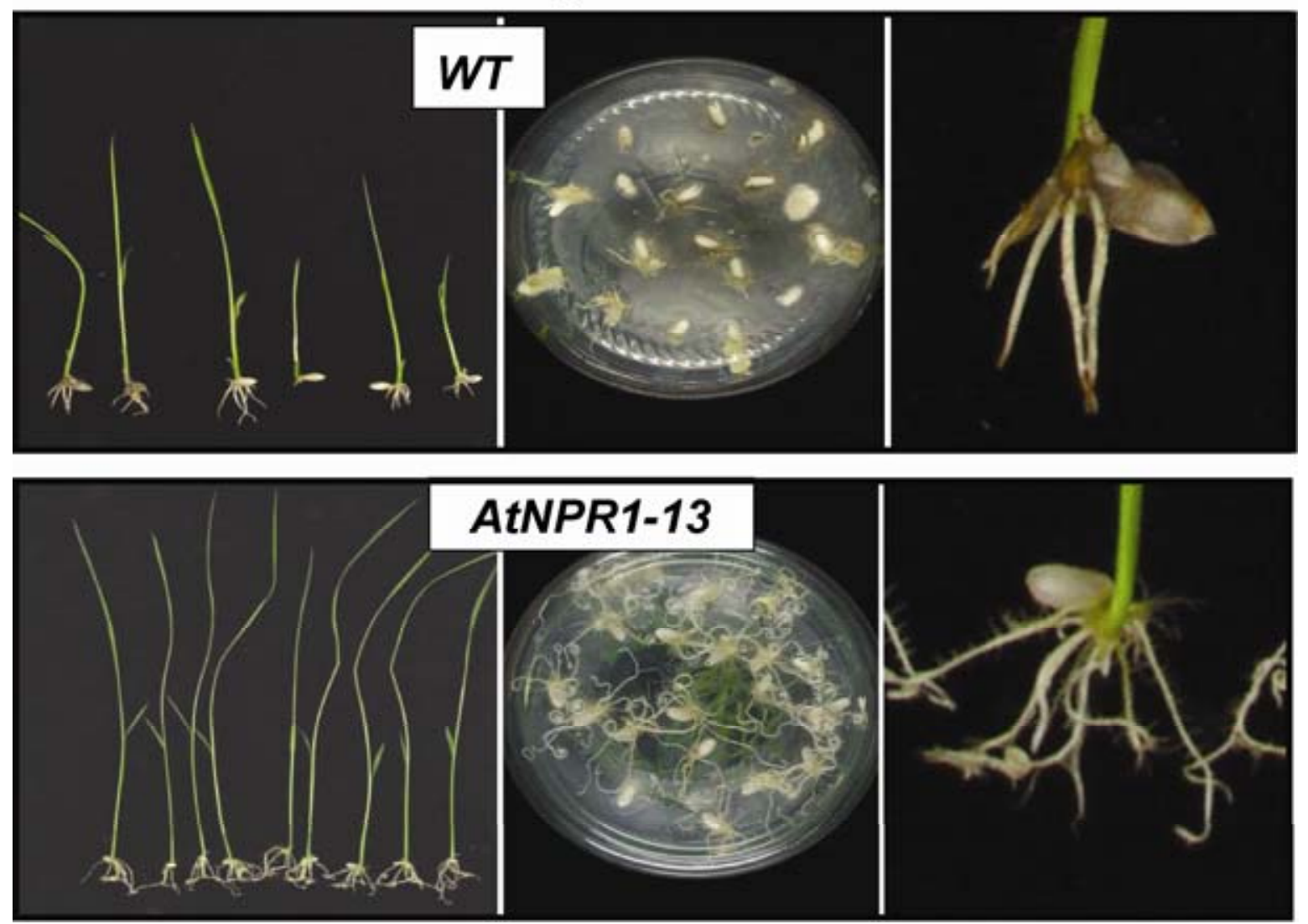

Fig. 4. Resistance of AtNPR1 plants to the bacterial foot rot Erwinia chrysanthemi. Disease resistance assays were carried out twice with three independent AtNPRl lines. Seed were germinated for $24 \mathrm{~h}$, vacuum infiltrated with a bacterial culture (10 $\left.{ }^{6} \mathrm{CFU}\right)$, and then allowed to continue germination. Pictures were taken 10 days after bacterial infiltration. A detailed view of AtNPRl and wild-type (WT) roots is shown in the middle and right panels. This experiment is one of the three performed which gave similar results. 
expression in both transgenic and IR64 plants at 7 dpi) whereas, in Gigante plants, RYMV infection induced tIF5A but not OSPR10A expression (as was also observed in virally infected wild-type plants) (results not shown).

Because of the close connection between expression of $R D R I$ and antiviral defenses, we searched into the rice genome for the presence of $R D R l$ sequences. A gene encoding a protein showing a high degree of identity to the AtRdRPl and $N t R D R l$ genes was identified in the rice genome (accession number NM00105486) (Dean et al. 2005). The protein encoded by this rice gene shares 63 and $64 \%$ identical amino acid residues with AtRdRP1 and NtRdRP1, respectively. A phylogenetic analysis demonstrated that the gene identified in the rice genome clustered together with the Arabidopsis and tobacco RDRl genes (AtRdRPl and NtRdDPl), this gene being more distantly related to the Arabidopsis $R D R 2$ and $R D R 6$ genes (Fig. 6B). We named this rice gene OsRDRl. By using OsRDRl-specific PCR primers, we demonstrated that, like

A

AtNPR1

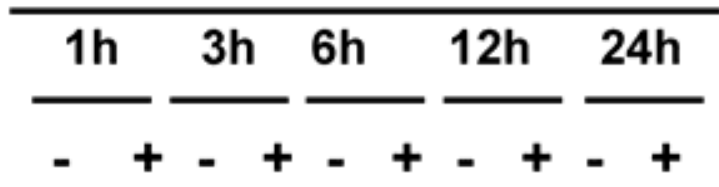

OsPR1b

PBZ
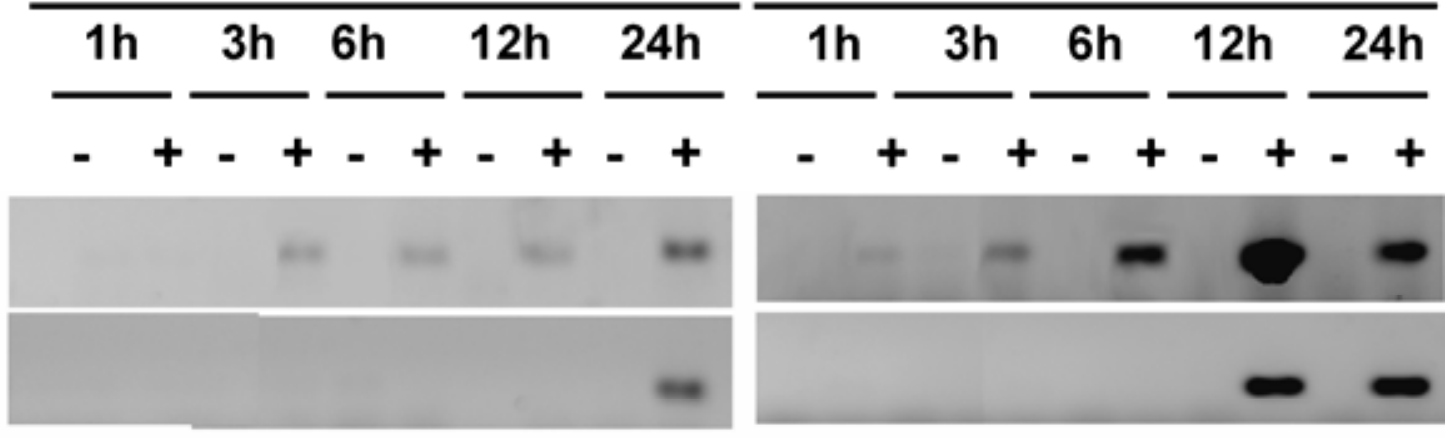

OsPR10

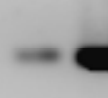

$T L P(P R 5)$

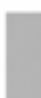

\author{
Actin
}
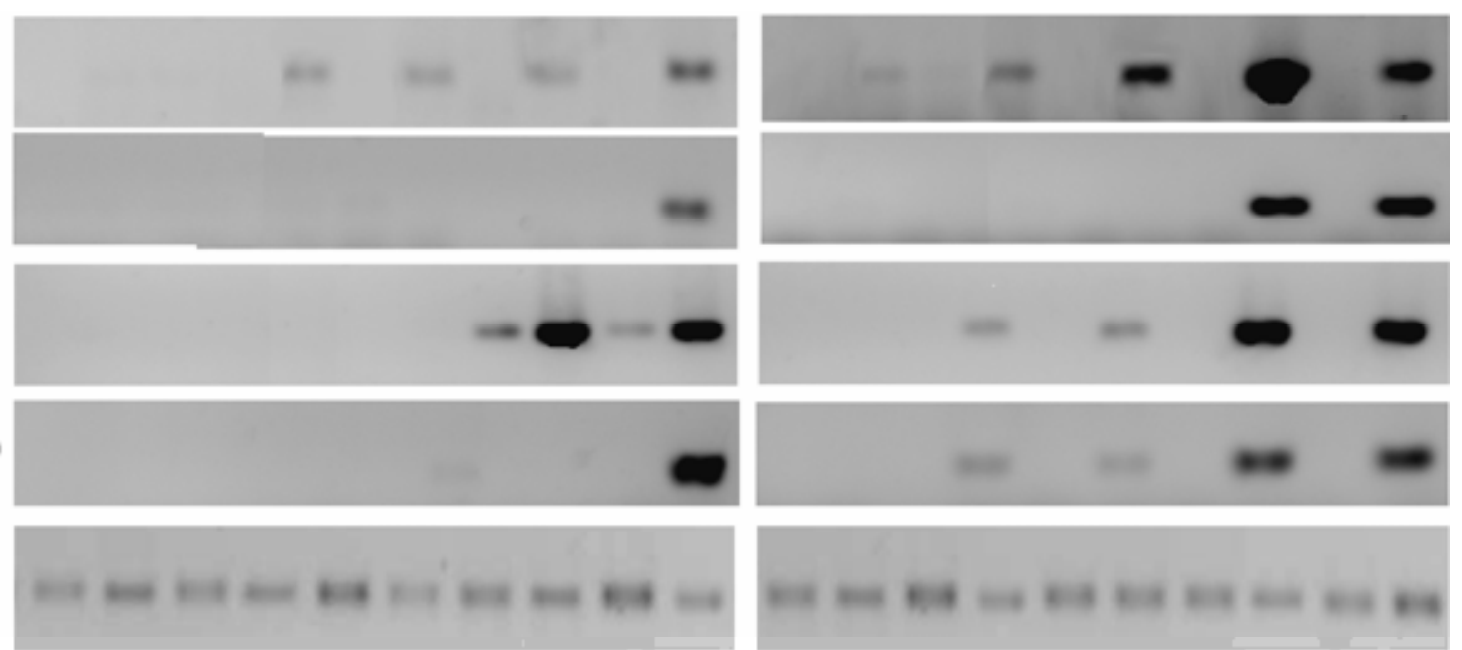

Actin

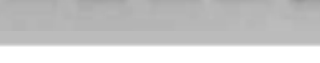
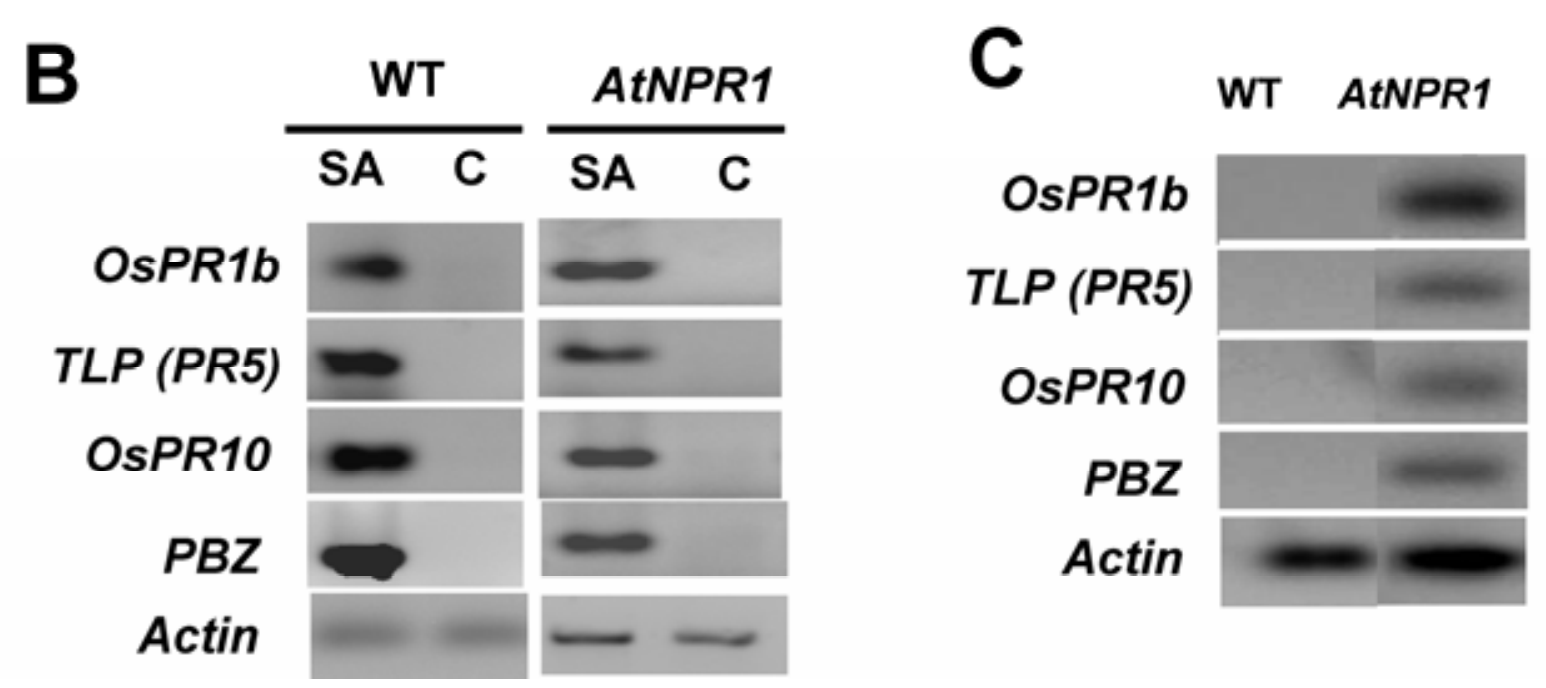

Fig. 5. Expression of rice defense genes in AtNPRI and wild-type (WT) plants. Results for the AtNPRI line 13 are shown; similar results were obtained for the AtNPR1 lines 1, 2, and 24. Reverse-transcriptase polymerase chain reaction (RT-PCR) was performed using specific primers for the indicated genes: OsPR1b, PBZ1, OsPR10, and TLP (PR5). A, RT-PCR analysis of Magnaporthe oryzae-infected (+) and noninfected (-) leaves from WT and AtNPR1 plants. Each RNA was prepared from a pool from samples of leaves from eight plants at the three-leaf stage. Transcripts for the rice defense genes accumulated faster and at higher levels in fungus-infected AtNPR1 plants than in fungus-infected WT plants. A low level of OsPR10 transcript accumulation was consistently observed in control, noninfected WT plants (12 and $24 \mathrm{~h})$. B, Effects of treatment with salicylic acid (2 mM) on the expression of rice defense genes. Control and transgenic plants were treated for $24 \mathrm{~h}$. C, Expression of rice defense genes in leaves of transgenic and WT plants grown in growth chamber for 5 days. 
NtRDRl and AtRDRl, OsRDRl is also induced by SA treatment in rice plants (Fig. $6 \mathrm{C}$ ).

Next, the effect of RYMV infection on OsRDRl gene expression was analyzed in wild-type and transgenic plants. In the absence of viral infection, OsRDRl expression is not detected in leaves of wild-type plants (Fig. 6D, 7, 10, and $14 \mathrm{dpi}$, upper panels). Upon infection of wild-type plants by RYMV, OsRDRl expression was not detected in either locally inoculated leaves or systemic leaves at $10 \mathrm{dpi}$, although a certain level of expression was observed in systemic leaves at $14 \mathrm{dpi}$ (Fig. 6D). Contrary to this, OsRDRl gene expression occurred in both locally inoculated leaves (7 dpi) and systemic leaves (10 and 14 dpi) of RYMV-infected rice expressing AtNPRI (Fig. 6D). The RYMV-induced expression of OsRDRI increased with time, with higher levels of $O S R D R l$ transcripts accumulating at 14 than at $10 \mathrm{dpi}$ in leaves of AtNPRI plants. In other experiments, we confirmed that transcripts of the AtNPRI transgene accumulated at similar levels in leaves of AtNPRI plants, excluding the possibility of $O S R D R 1$-mediated transgene silencing in transgenic plants (results not shown).

\section{Enhanced susceptibility \\ of AtNPR1 rice plants against RYMV.}

Knowing that the pattern of expression of RYMV-responsive rice genes is misregulated in AtNPRI plants, we investigated whether transgenic expression of AtNPRI in rice has an influence on the resistance against RYMV. Toward this end, T2 homozygous plants of five independent transgenic lines (lines 1, 2, 13, 24, and 27) and wild-type Senia plants were challenged with RYMV. Four rice cultivars, the two indica cvs. Gigante and IR64 (highly resistant and highly susceptible to RYMV, respectively) and the two japonica cvs. Azucena and Nipponbare (partially resistant and partially tolerant to RYMV, respectively) were used as reference cultivars in these assays (Albar et al. 1998; Ndjiondjop et al. 1999).

For challenge experiments, transgenic and control plants (70 plants per line) were mechanically inoculated with RYMV particles. Thirty plants of the same lines were mock inoculated with buffer and grown under the same experimental conditions. Development of disease symptoms and viral accumulation were monitored with time on both locally inoculated leaves (7 dpi) and newly developed leaves (systemic leaves, 10, 14, 21, and 28 dpi) (Figs. 7 and 8). At 7 dpi, symptoms characteristic of RYMV infection were already seen on the inoculated leaves of the highly susceptible cv. IR64 but not in the wild-type Senia or AtNPR1 plants. However, at 10 to $14 \mathrm{dpi}$, all the transgenic rice lines developed symptoms of infection in systemic leaves. Thus, their leaves showed disperse chlorotic spots progressing to streaking lesions (Fig. 7A). By this time, disease symptoms were less evident in leaves of wild-type (Senia) plants. At 21 dpi, all transgenic plants exhibited pale, mottled leaves, disease symptoms being clearly more severe in transgenic plants than in wild-type plants (Fig. 7A). At $28 \mathrm{dpi}$, AtNPR1 lines showed clear mottling and generalized yellowing, whereas wild-type plants appeared to be much healthier (Fig. 7B).

Scoring of symptom severity in wild-type and transgenic plants was performed using a 1-to-9 scale of the Standard Evaluation System for rice (SES), where $1=$ no symptom and $9=$ typical susceptible-type lesion (as indicated below). Symptom scale 5 was the typical response for the wild-type Senia and Nipponbare cultivars whereas symptom scale 7 was observed for all five AtNPR1 rice plants assayed in this work (Fig. 7A, SES website).

Next, the level of virus accumulation was determined in locally inoculated leaves ( $7 \mathrm{dpi})$ as well as in systemic leaves (10, 14, and $21 \mathrm{dpi}$ ). Results are presented in Figure 8. At $7 \mathrm{dpi}$, the level of accumulation of RYMV in leaves of both transgenic and

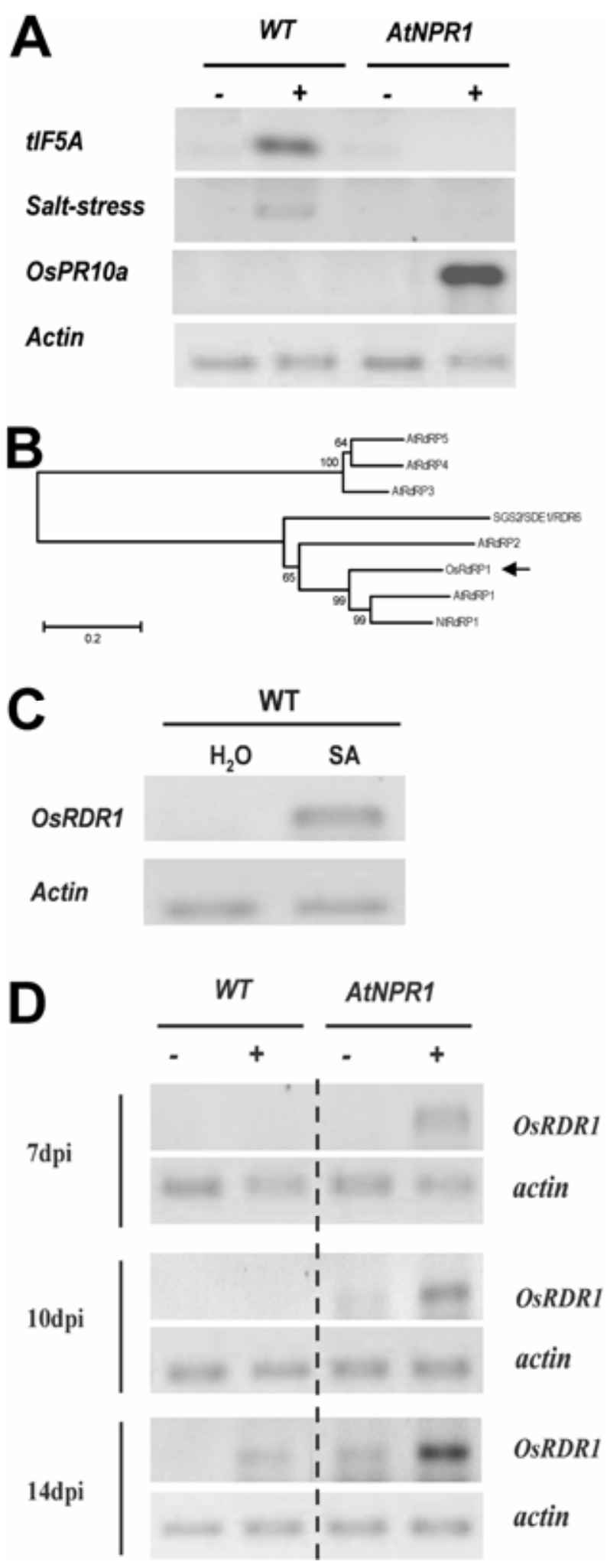

Fig. 6. Expression of Rice yellow mottle virus (RYMV)-associated genes in AtNPR1 and wild-type (WT) plants. A, Reverse-transcriptase polymerase chain reaction (RT-PCR) analysis of locally inoculated leaves (7 days postinoculation [dpi]) from wild-type (WT) and AtNPRI plants using specific primers for the $t I F 5 A$, salt-stress-induced protein, and PR10A genes. B, Phylogenetic analysis of the relationship between the OsRDR1 protein and the Arabidopsis and tobacco RNA-dependent RNA polymerase (RDR) proteins. C, Effect of treatment with salicylic acid (2 $\mathrm{mM}$ ) on $O s R D R 1$ gene expression in WT rice. D, RT-PCR analysis of locally inoculated (7 dpi) and systemically infected leaves of RYMVinfected plants (10 and $14 \mathrm{dpi}$ ) using specific primers for the OsRDR1 gene. 

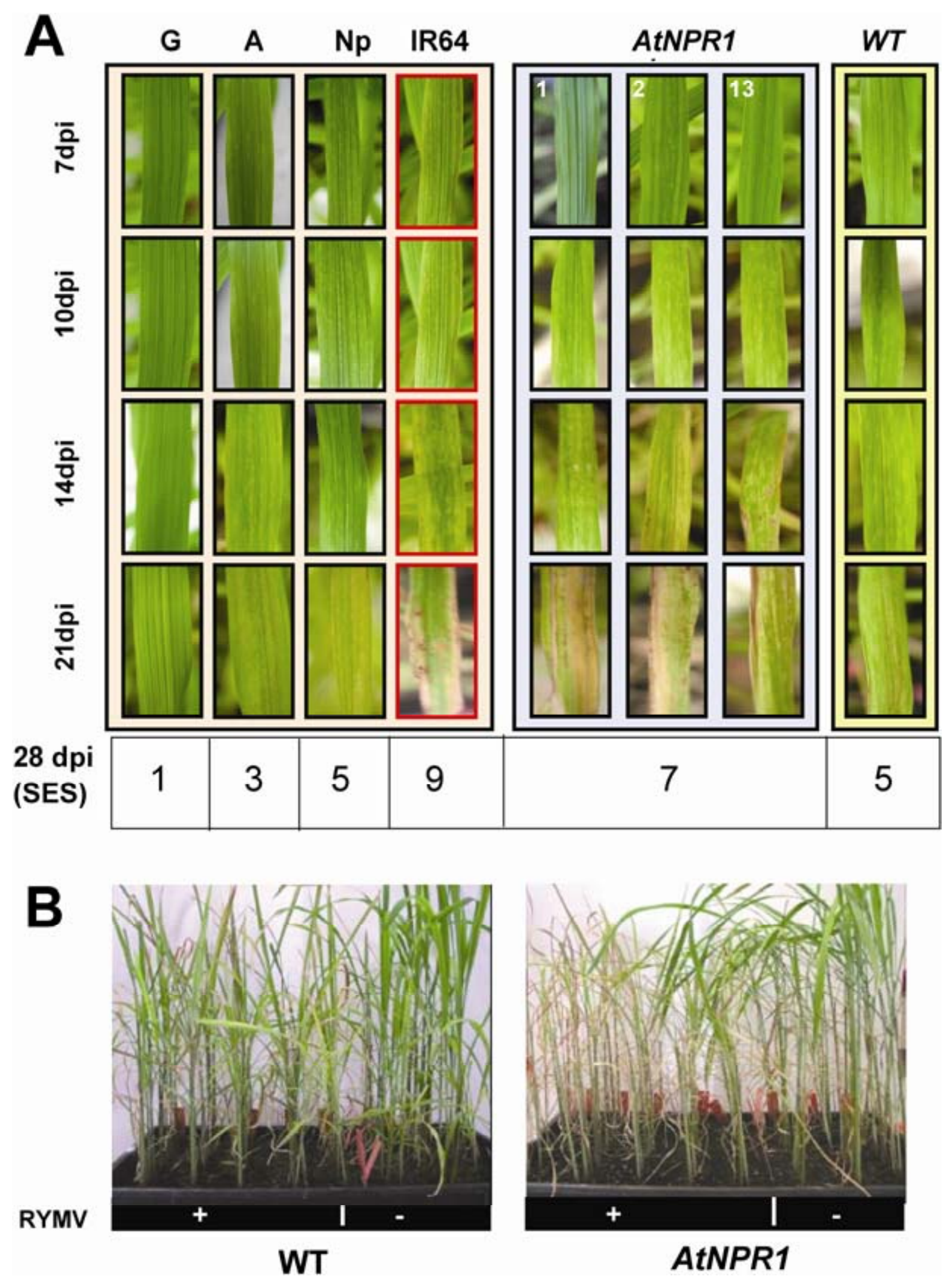

Fig. 7. Susceptibility of AtNPR1 plants to Rice yellow mottle virus (RYMV). Five independent AtNPR1 lines were assayed (lines 1, 2, 13, 24, and 27). Results for the AtNPRI lines 1, 2, and 13 are presented (similar results were obtained for the AtNPRI lines 24 and 27). A, Symptom severity in leaves of transgenic and wild-type (WT) plants inoculated with RYMV. Photographs were taken at 7 days postinoculation (dpi) (locally inoculated leaves) and at 10, 14, and 21 dpi (systemic leaves). Reference cultivars used in this study were Gigante (G, highly resistant), Azucena (A, partially resistant), Nipponbare (Np, partially tolerant), and IR64 (highly susceptible). Numbers at the bottom indicate the response of the different lines to RYMV infection according to the standard evaluation system for rice. Statistically significant differences between AtNPR1 lines and WT plants are indicated by $*(P<0.001$, analysis of variance with Tukey's highly significant difference; $\alpha=0.05$ ). B, Phenotype of transgenic and WT plants inoculated with RYMV. The picture was taken at 28 dpi. Experiments were carried out three times. Similar results were observed in all the experiments. 
wild-type plants was lower than in Azucena or Nipponbare plants (partially resistant and partially tolerant to RYMV, respectively). Consistently with the appearance of virus symptoms, the susceptible control cv. IR64 accumulated high levels of RYMV in both local and systemic leaves whereas the resistant cv. Gigante accumulated RYMV at very low levels. At 10 to $14 \mathrm{dpi}$, the level of virus accumulation in the systemic leaves of all the transgenic lines was significantly lower than in systemic leaves of wild-type plants. By this time, however, symptom severity was higher in systemic leaves of transgenic plants than in systemic leaves of wild-type plants (Fig. 7). Thus, there was no correlation between virus content and symptom expression in systemic leaves of transgenic plants when compared with wild-type plants. Virus content in systemic leaves of transgenic lines progressively increased from 10 to 14 and $21 \mathrm{dpi}$. At $21 \mathrm{dpi}$, the level of viral accumulation did not differ among the different transgenic and wild-type plants, although transgenic lines still developed more severe symptoms of infection than wild-type plants.

Together, and consistent with the observed misregulation of RYMV-responsive genes, these results revealed that constitutive expression of AtNPRl in transgenic rice led to an enhanced disease susceptibility to RYMV infection.

\section{AtNPR1 negatively modulates expression}

of salt- and drought-associated rice genes.

We investigated whether transgenic expression of AtNPRl in rice has an effect on the expression of genes which are known to play a role in adaptation to drought and high salinity conditions and, if so, whether AtNPRl plants exhibit a phenotype of tolerance or sensitivity to high salt conditions. We selected specific rice genes whose expression was described to be upregulated in response to drought and high salinity, namely the rab21, a rice dehydrin (accession number AK109096), salT (salt-stress-induced protein, accession number AF001395), and dipl (dehydration-stress inducible protein 1, accession number AY587109) genes (Claes et al. 1990; Oh et al. 2005; Rabbani et al. 2003). The expression of these genes was analyzed by RT-PCR in roots of wild-type and transgenic plants under salt stress conditions $(150 \mathrm{mM} \mathrm{NaCl})$. Under normal growth conditions, transgenic expression of AtNPR1 in rice does not affect the expression of any of the genes under study (results not shown). In the case of the rab21 gene, induction of its expression in response to salt treatment was delayed in transgenic plants compared with wild-type plants (Fig. 9). Moreover, rab21 transcripts accumulated at lower levels in transgenic plants compared with wild-type plants. A delayed induction of salT gene expression was also observed in AtNPRI lines compared with wild-type plants. Finally, induction of dipl gene expression occurred at the same time after the onset of salt treatment $(3 \mathrm{~h})$ in transgenic and wild-type plants. In contrast to wild-type plants, accumulation of dipl transcripts progressively decreased with time (Fig. 9). Overall, this study revealed that expression of AtNPRI in rice causes a delay or reduces the intensity of expression of the salt-associated rab21, salT, and dipl rice genes.

\section{AtNPR1 rice plants are hypersensitive to salt and drought stresses.}

The tolerance of transgenic rice plants to drought and salt stresses was compared with that of control plants. Stress tolerance was evaluated based on the percentage of plants that survived after a period of drought or salt treatment. For this study, 2-week-old transgenic plants (lines $1,2,13$, and 24; $n=72$ plants per line) and wild-type plants (82 plants) were assayed. The tolerance of the transgenic plants to high-salt stress was examined by keeping the transgenic plants in $\mathrm{NaCl}$ at different concentrations $(50,100$, and $200 \mathrm{mM} \mathrm{NaCl})$ for 5 days and then growing them for 15 days with normal watering. All transgenic lines exhibited enhanced sensitivity to salt stress (Fig. 10; Table 1). The phenotypic difference between wildtype and transgenic plants was already observed after treatment with only $50 \mathrm{mM} \mathrm{NaCl}$. At 2 weeks after treatment with $50 \mathrm{mM} \mathrm{NaCl}$, none of the transgenic plants survived, whereas $96 \%$ of the wild-type plants survived.

Knowing that transgenic lines show a reduction in their size compared with wild-type plants, there was the possibility that a reduction in the plant size might have an effect on tolerance
A
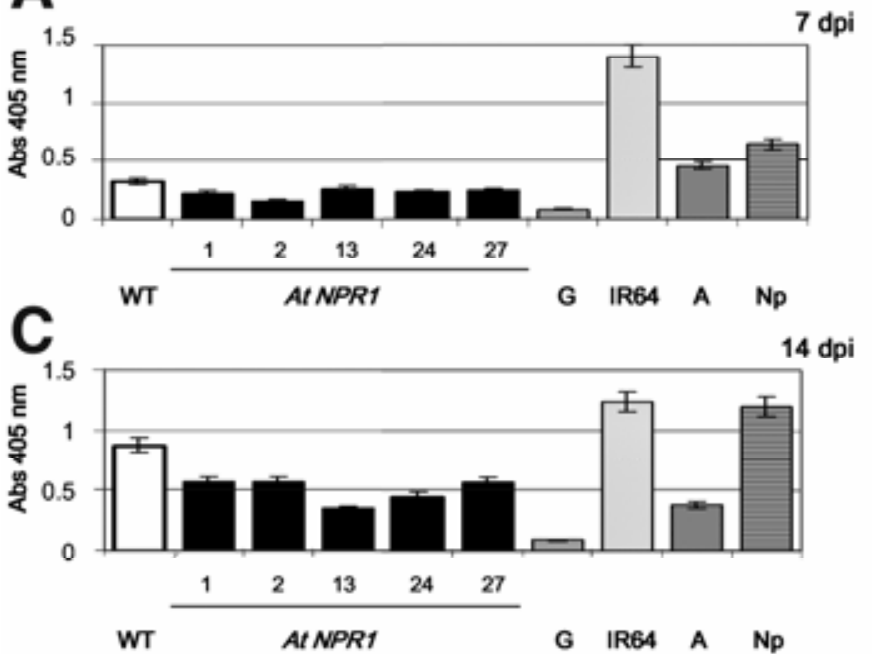

B
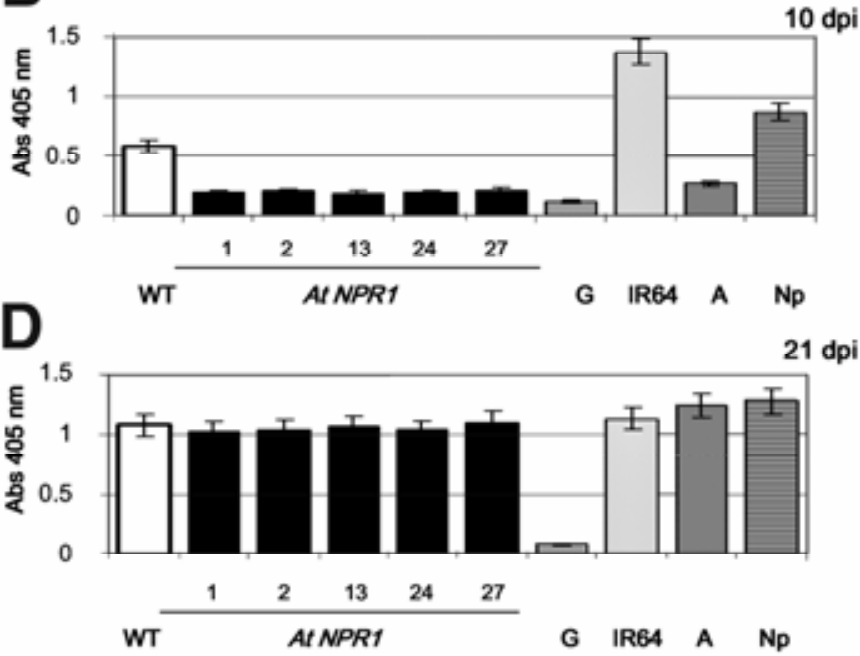

Fig. 8. Virus accumulation in leaves of transgenic and wild-type (WT) plants inoculated with Rice yellow mottle virus (RYMV). WT (white bars), transgenic lines (black bars) and reference cultivars (dashed bars) Gigante (G), Azucena (A), Nipponbare (Np), and IR64. Leaves from nine plants for each line were pooled and the virus content determined by enzyme-linked immunosorbent assay using an antibody generated against the coat protein as described (N'Guessan et al. 2000). Accumulation of RYMV in A, locally inoculated leaves at 7 days postinoculation (dpi) and B through D, systemically infected leaves at 10, 14, and $21 \mathrm{dpi}$, respectively, from WT, AtNPR1 lines, and the control cvs. Gigante (G), IR64, Azucena (A), and Nipponbare (Np) is presented. Statistically significant differences between AtNPRl lines and WT plants are indicated by $*(P<0.001$, analysis of variance with Tukey's highly significant difference; $\alpha=0.05$ ). 
to salt stress. During the course of this work, salt tolerance assays were also carried out with 2-day-germinated seedlings from wild-type and transgenic lines. Seedlings were also subjected to salt treatment for 5 days. Results obtained in these experiments also revealed a higher susceptibility to salt treatment in AtNPR1 lines compared with wild-type plants (results not shown).

To determine the tolerance of transgenic rice to drought, we grew transgenic and wild-type plants without watering for 9 days and then supplying water again for 2 weeks. All transgenic plants, but not wild-type plants, showed wilting and drought-induced rolling of young leaves (Fig. 10). Whereas $90 \%$ of the wild-type plants survived 9 days without water, the survival rate for transgenic lines ranged from 46 to $61 \%$, depending on the line (Table 2). From these results, it is concluded that expression of AtNPRl in transgenic rice causes hypersensitivity to both salt and drought stresses.

\section{DISCUSSION}

The development of genetically engineered disease-resistant plants comes as a result of efforts to understand the molecular mechanisms involved in the plant defense response against pathogens. A better understanding of the function of regulatory components of the plant defense response, and the target genes and traits that they regulate, is of great importance not only for basic research in plant biology but also for crop protection. Presumably, the use of regulatory genes of the plant defense mechanisms might allow the activation of the expression of multiple defense genes and, accordingly, better levels of protection are expected compared with strategies based on the use of a single gene or a combination of individual genes encoding antimicrobial proteins.

Compelling evidence exists that AtNPR1, when introduced into a plant, confers resistance to fungal and bacterial diseases,

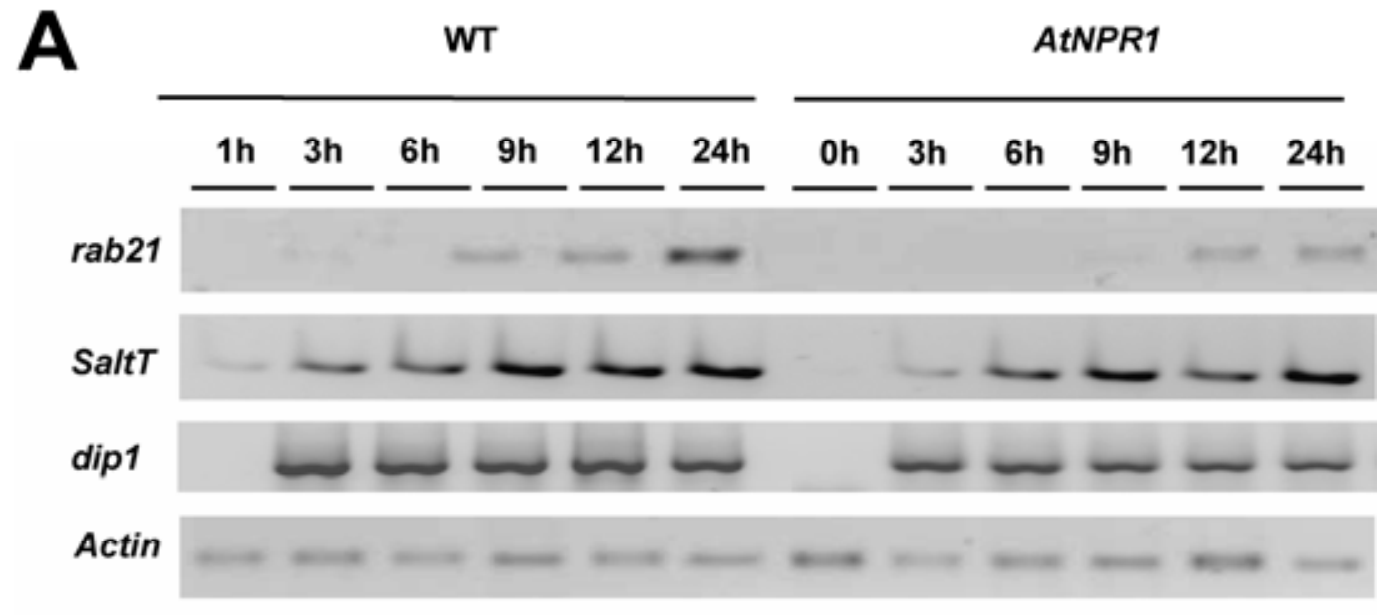

B
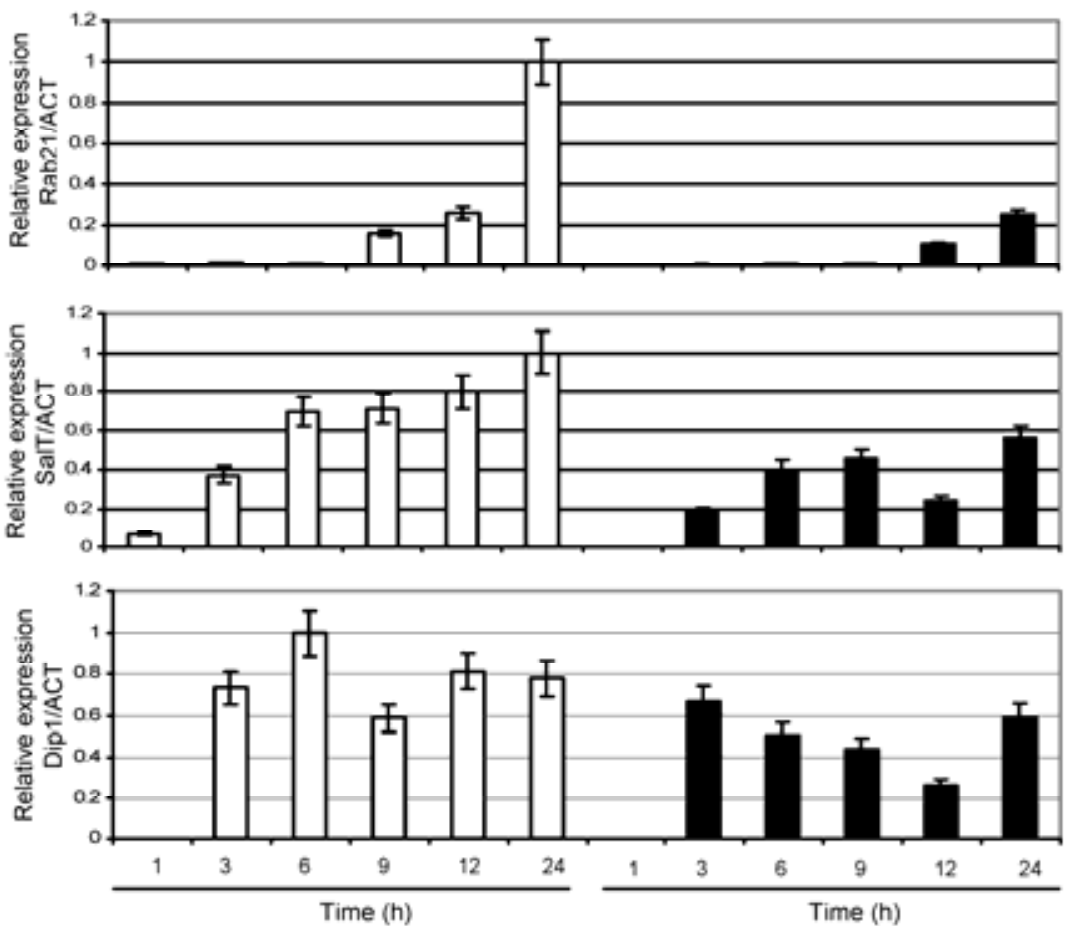

Fig. 9. Expression of salt- and drought-associated rice genes rab21, saltT, and dip1 in wild-type (WT) and transgenic plants. T2 homozygous AtNPR1 rice lines and WT plants were grown in Murashige-Skoog medium for 7 days and then exposed to water (control) or $150 \mathrm{mM} \mathrm{NaCl} \mathrm{for} \mathrm{1,} \mathrm{3,} \mathrm{6,} \mathrm{9,} \mathrm{or} 24 \mathrm{~h}$. A, Representative results obtained by reverse-transcriptase polymerase chain reaction analysis of the rab21, salT, and dipl genes in AtNPR1 line 1 are shown. B, Relative changes of rab21, saltT and dip1 transcript levels plotted to the highest value after normalization with Actin 1. Values represent the means \pm standard deviation of three independent experiments in AtNPR1 line 1. Similar results were observed for lines 2 and 13. 


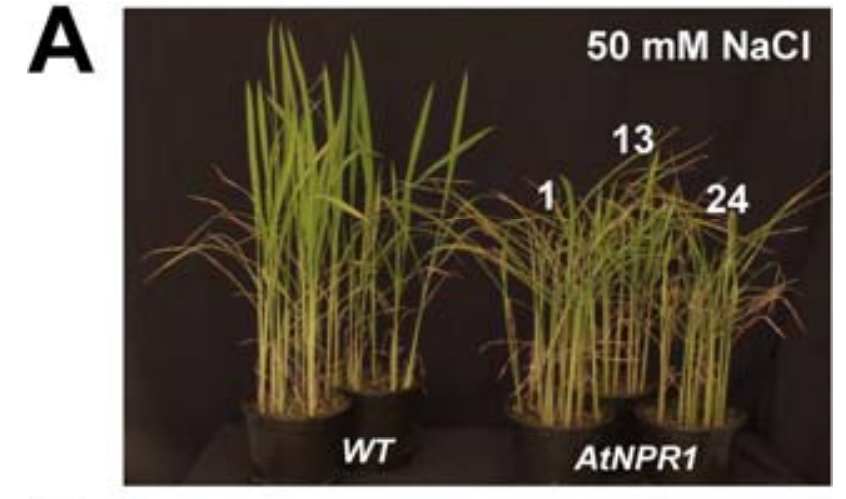

B

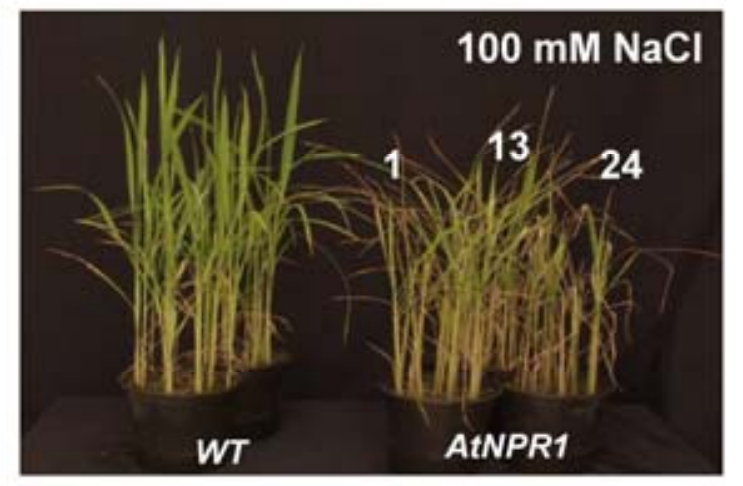

C

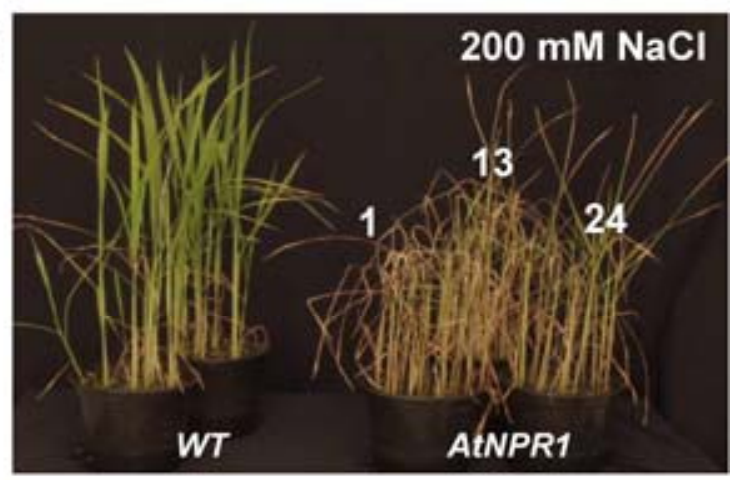

D

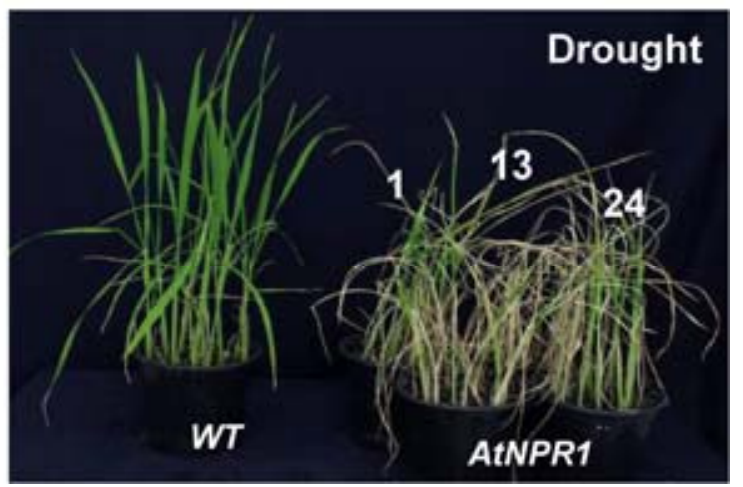

Fig. 10. Sensitivity of AtNPRI plants to salt and drought stress. All four independently generated transgenic lines assayed in this work (lines 1, 2, 13 , and 24 and T2 homozygous lines) showed hypersensitivity to salt and drought stress. A through $\mathbf{C}$, Phenotype of plants during salt stress conditions. Plants were grown in the greenhouse for 2 weeks, treated with $\mathrm{NaCl}$ $(50,100$, and $200 \mathrm{mM})$ for 5 days, and then irrigated with water for 2 weeks. D, Drought stress; water was withheld for nine days and then plants were supplied with water again for 2 weeks. The pictures were taken at 15 days after salt or drought treatment. Assays to determine tolerance to salt and drought stress were carried out four times and at different times of the year. In each experiment, 84 wild-type (WT) plants and 73 plants per transgenic line were used. Similar results were observed in all the assays. which led to the proposal of AtNPRI as a promising candidate gene for engineering broad-spectrum disease resistance in transgenic plants. In this work, the Arabidopsis AtNPRl gene was introduced into rice plants. Both positive and negative effects caused by AtNPRI expression in rice were found. Thus, the expression of AtNPRl in rice has a negative effect on plant growth and productivity. Moreover, AtNPRl plants develop spontaneous lesions when growing under suboptimal conditions (growth chamber). An important difference between greenhouse and growth -chamber conditions is the total light intensity $(5,000$ to 8,500 lux in the growth chamber and 12,000 to 20,000 lux in the greenhouse). In this respect, lesion formation in Taipei 309 rice plants expressing AtNPRl was already reported by Fitzgerald and associates (2004). However, whereas, in AtNPRI Senia plants, the lesions appeared 2 to 3 days after transferring the plants to the growth chamber (present work), in AtNPRl Taipei 309 plants, the lesions were apparent only after 2 to 3 weeks under growth-chamber conditions (Fitzgerald et al. 2004).

Expression of the AtNPRl gene in rice confers protection against fungal ( $M$. oryzae and $F$. verticillioides) and bacterial (E. chrysanthemi) pathogens, further supporting a role for the AtNPRl gene in resistance to these types of pathogens in rice. The fungus $M$. oryzae was chosen for this study because this fungus causes rice blast, the most important fungal disease of cultivated rice (Talbot 2003). Breeding of durable resistance to M. oryzae is a difficult problem not only because of the high degree of pathogenic variability of this fungus but also because of the large number of fungal races encountered in the field population. The fungus $F$. verticillioides, formerly known as $F$. moniliforme Sheldon, is also an important fungal pathogen of rice and the causal agent of the bakanae disease. $F$. verticillioides causes a decrease not only in quantity but also in quality of rice by producing toxins, namely fumonisins, that affect

Table 1. Effect of salt treatment on AtNPR1 rice plants ${ }^{\mathrm{a}}$

\begin{tabular}{lccc}
\hline & & \multicolumn{2}{c}{ Survival no. $(\%)^{\mathbf{b}}$} \\
\cline { 3 - 4 } Lines & No. of plants & $\mathbf{7}$ days & $\mathbf{1 5}$ days \\
\hline Wild type & 84 & $84(100)$ & $81(96)$ \\
AtNPR $1-1$ & 72 & $6(9)^{*}$ & 0 \\
AtNPRl-2 & 72 & $8(11)^{*}$ & 0 \\
AtNPRl-13 & 72 & $10(14)^{*}$ & 0 \\
AtNPR $1-24$ & 72 & $8(11)^{*}$ & 0 \\
\hline
\end{tabular}

a Two-week old plants were treated with $50 \mathrm{mM} \mathrm{NaCl}$ for 5 days and then irrigated with water. The number of plants used from wild-type and transgenic (lines 1, 2, 13, and 24) is shown.

b Number of plants that survived salt treatment after a period of recovery of 7 or 15 days. Data represent means \pm standard deviation of four independent experiments. Numbers in parenthesis indicate the percentage of surviving plants; * indicates that statistically significant differences between AtNPR1 and wild-type lines were observed $\left(\chi^{2}\right.$ test, $\left.P<0.001\right)$.

Table 2. Survival of AtNPR1 plants following drought treatment ${ }^{\mathrm{a}}$

\begin{tabular}{lcc}
\hline Lines & No. of plants & Survival no. $(\%)^{\mathbf{b}}$ \\
\hline Wild type & 84 & $65(90)$ \\
AtNPR $1-1$ & 72 & $38(53)^{*}$ \\
AtNPR $1-2$ & 72 & $45(63)^{*}$ \\
AtNPR $1-13$ & 72 & $33(46)^{*}$ \\
AtNPR $1-24$ & 72 & $44(61)^{*}$ \\
\hline
\end{tabular}

${ }^{a}$ Water was completely withheld from 2-week-old plants for 9 days and then watering was resumed for 15 days. The number of plants used in this study, both wild-type and transgenic (lines 1, 2, 13, and 24) plants, is shown.

${ }^{\mathrm{b}}$ Number of plants that survived and survival rate (\%) for each line after 15 days of rewatering. Data represent means \pm standard deviation of four independent experiments. Numbers in parenthesis indicate the percentage of surviving plants; * indicates that statistically significant differences between AtNPRI and wild-type lines were observed ( $\chi^{2}$ test, $P<0.005$ ). 
human and animal health (Nelson et al. 1993). Finally, the gramnegative bacterium $E$. chrysanthemi, the causal agent of the foot rot disease of rice, represents another major constrain for rice production (Goto 1979). Results here presented show that AtNPRl confers resistance against foliar pathogens as well as against seed and root pathogens, illustrating the important role that AtNPRI plays in the plant defense response even early in plant development. On the other hand, studies carried out in Arabidopsis suggested that the plant defense responses may be tailored to the attacking pathogen, with SA-dependent defenses acting against biotrophs, and jasmonic (JA)- and ethylene (ET)dependent responses acting against necrotrophs (Glazebrook 2005). In particular, AtNPR 1 has been implicated in resistance against biotrophic pathogens that requires SA signaling. The two fungal pathogens used in this study, M. oryzae and $F$. verticillioides, have been described as hemibiotrophic and necrotrophic fungi, respectively, whereas Erwinia spp. are bacterial necrotrophs. To our knowledge, no information is currently available about requirements for a specific signaling pathway, such as the SA-, JA-, or ET-dependent signaling pathway, during the rice response to these particular fungal and bacterial pathogens.

By examining the expression of marker genes of the endogenous defense response, we determined that AtNPRI plants are in a primed state, these plants exhibiting a faster and stronger activation of rice defense genes during pathogen infection compared with wild-type plants. Priming of defense-related genes is then consistent with the disease resistance phenotype observed in these plants. Here, it is worthwhile to mention that, although molecular information is available on the induced priming phenomenon in the dicotyledoneae (Conrath et al. 2006), this information is largely missing for monocotyledoneae, including the most important agronomic cereals. In this respect, our group recently reported a sucrose-mediated priming of defense responses in rice (Gómez-Ariza et al. 2007).

On the other hand, it is well known that the levels of SA dramatically increase in response to pathogen attack and during SAR in Arabidopsis and tobacco plants (Dempsey et al. 1999). In rice, however, the endogenous levels of SA are very high and its level does not change significantly after infection. The important question, then, is whether SA has a central role in induced defense responses in rice. Recent studies have shown that the signaling pathways downstream of SA are evolutionally divergent between rice and Arabidopsis (Shimono et al. 2007). When the SA responsiveness of the rice genes showing enhanced responses during pathogen infection in AtNPR1 rice plants ( $P R 1 b, T L P, O S P R 10$, and $P B Z 1)$ was examined, we found that these genes were strongly activated by treatment with SA. Then, the AtNPRI-mediated priming of defense gene expression in AtNPRl rice plants correlated well with the observed SA responsiveness of these genes. Future research on the AtNPRl-mediated priming mechanisms will allow a more comprehensive view of this phenomenon in rice plants.

Results presented here revealed novel functions for AtNPRI in controlling the plant response to viral pathogens, particularly to RYMV. Since its early description in 1974 (Bakker 1974), RYMV has become a model virus in rice. RYMV is a typical member of the genus Sobemovirus. The RYMV genome is a single-stranded messenger-sense RNA (ssRNA+) (Fargette et al. 2004). Although partial resistance is widely distributed in $O$. sativa cultivars, only some rare cultivars for the cultivated $O$. sativa and $O$. glaberrima species exhibit high resistance to RYMV (Ndjiondjop et al. 1999; Thottappilly and Rossel 1993). However, a recessive rice-resistant gene against RYMV encoding the eukaryotic translation initiation factor $4 \mathrm{G}$ (eIF4G) has been recently described (Albar et al. 2006). Results presented here show that AtNPRI interferes with the normal expression of rice genes which have been associated with the rice response to RYMV, the $t I F 5 A$, salt-stress-induced protein, PRIOA, and OsRDRl genes. The observed AtNPRl-mediated misregulation on the expression of RYMV-responsive rice genes has important consequences for the rice plant, the AtNPR1 rice plants exhibiting enhanced susceptibility to RYMV infection. An intriguing aspect of this study came from the observation that, during the initial phase of systemic infection of AtNPRl plants by RYMV, there was no correlation between virus content and disease severity. By measuring the accumulation of RYMV in systemically infected leaves (10 and $14 \mathrm{dpi}$ ), we observed that RYMV-infected AtNPRl plants showed a lower level of accumulation of RYMV particles compared with RYMV-infected wild-type plants. Systemically infected leaves of transgenic plants, however, exhibited more severe disease symptoms than systemically infected leaves of wild-type plants. One possible explanation for the reduced level of viral accumulation in leaves of transgenic plants compared with wild-type plants is that the virus spreads to a lesser extent in the vascular tissue from the initial infection site during the early stages of systemic infection. It is tempting to speculate that the observed differential reaction to RYMV infection between transgenic and wild-type plants might be caused by the interference of AtNPR1 with host factors which are usually positive regulators of the response against viral infection. An alternative explanation for the discrepancy observed between viral content and symptom intensity in AtNPR1 plants could be that AtNPR1 overexpression might cause an overreaction in the defense response to viral infection, leading to more severe disease symptoms.

During the course of this work, we identified a rice $R D R I$ gene, the $O s R D R 1$ gene, showing responsiveness to SA. RDR1 proteins are known to mediate RNA silencing pathways regulating defense against viruses (Baulcombe 2004). Leaves of AtNPRl lines were characterized by strikingly higher levels of $O s R D R 1$ expression compared with leaf tissues of wild-type plants. Theoretically, an increase in $O s R D R l$ expression might result in a reduction of the accumulation of viral RNAs through the activation of RNA-silencing pathways and degradation of viral RNAs and, thereby, lowering the amount of viral particles in leaves of transgenic plants. Then, this mechanism might explain the lower level of virus particles observed in transgenic plants compared with wild-type plants at the early stages of the infection process. A similar function promoting turnover of viral RNAs has been postulated for the orthologous Arabidopsis (AtRdRPl) and tobacco (NtRdRPl and NbRdRPl) genes, for which induction by treatment with SA and viral infection has been also described (Yu et al. 2003). AtNPRl rice plants may be useful to further explore whether AtNPRl interferes with RNA silencing mechanisms in rice plants during RYMV infection. It will also be interesting to determine the effect of AtNPRl on the response of rice plants to viruses other than RYMV.

Mechanisms conferring resistance to fungi and bacteria are usually considered to function independently from those involved in resistance to viruses. Results presented here, however, support the idea that some cross-talk exists among these pathways, AtNPRl functioning by priming the expression of rice defense genes involved in resistance against fungal pathogens while altering the normal expression of virally associated rice genes. In agreement with this, constitutive expression of AtNPRl in rice confers resistance to fungal and bacterial pathogens while exerting a profound, negative effect on viral resistance in rice.

Until now, AtNPRl has not been functionally characterized in relation to abiotic stresses, particularly to salt and drought stress. However, AtNPRI appears to be required for ozone- 
induced ethylene production and cell death (Rao et al. 2002). We found that AtNPRI negatively regulates the expression of genes functioning in salt- and drought-stress responses in rice, namely the rab21, salt T, and dipl rice genes. The observed negative regulation of salt or drought marker genes is accompanied by hypersensitivity to salt and drought stresses in AtNPRl plants. Taking into account the fact that signaling pathways involved in plant responses to salt and drought stress are largely overlapping (Seki et al. 2003; Zhu 2002), it is not surprising to find that $A t N P R 1$ rice plants are more sensitive to the two types of stress. Interestingly, it was reported that RYMV infection regulates the expression of genes for which a function has been traditionally associated with the plant response to salt stress, including the tIF5A, PR10A, and salt-associated protein genes studied in this work (Ventelon-Debout et al. 2004). This might explain why AtNPRl rice plants are negatively affected in their response to salt and drought stress as well as to the stress imposed by viral infection. Finally, all independent transgenic lines used in the present study exhibited the same phenotype (reduced size and productivity and development of spontaneous lesions), behavior under biotic and abiotic stress conditions, and transgene-mediated alterations in host gene expression excluding the possibility of an insertional effect caused by transgene integration into the rice genome.

To conclude, this study allowed us to correlate the transcript levels of endogenous genes associated with different types of stress, both biotic and abiotic, with the observed phenotype of AtNPR1 plants under these particular stress conditions. Collectively, the results presented here demonstrate the complexity of the roles played by AtNPRl in plant defense responses while illustrating the antagonistic relationships that occur between the various signaling pathways controlling the plant response to biotic and abiotic stresses. In other studies, a rice mitogenactivated protein kinase that negatively modulates resistance to fungal and bacterial pathogens and positively regulates abiotic stress tolerance was reported (Xiong and Yang 2003). One function of AtNPRI might be to provide a fine-tuning mechanism of the plant defense response and to coordinate responses associated with each type of stress. The possibility that AtNPR1 regulates defense gene expression through the concerted action of positive and negative regulators associated with each specific type of stress defense response should be considered. Negative effects of AtNPRI on defense gene expression might result from suppression of positive regulators of abiotic stress responses and antiviral defenses (i.e., by sequestering positive regulators of the type of stress). Taking into account that transgenic expression of AtNPRl in rice is associated with a penalty under situations of viral infection and abiotic stress conditions, the practical question is whether the resistance conferred by transgenic expression of AtNPRI in rice could be used to improve resistance to fungal and bacterial pathogens under field conditions. The results described in this study point to the need to further dissect the pathways in which AtNPRl is involved in disease resistance and tolerance to abiotic stresses in plants.

\section{MATERIALS AND METHODS}

\section{Plant material and growth conditions.}

Rice plants (O. sativa L. cv. Senia) were grown in the greenhouse at 26 to $28^{\circ} \mathrm{C}$ with a 18- and 6-h (day and night, respectively) cycle. When needed, plants were transferred to growth chambers $(5,000$ to 8,500 lux $)$ under the same diurnal cycle. For rice transformation, the Agrobacterium tumefaciens EAH105 was used to infect embryogenic callus derived from mature embryos according to Pons and associates (2000).
Construction of the plant expression vector and rice transformation.

The Arabidopsis NPR1 cDNA sequence (kindly provided by X. Dong, Duke University, Durham, NC, U.S.A.) was amplified from the pKEX4tr plasmid (Cao et al. 1997) with primers 5'-GCGGATCCACACGATGGACACCACCATTGA-3' and 5'GCGGATCCCACTAAGAGGCAAGAGTC-3' (underlined letters indicate the Bam $\mathrm{H} 1$ restriction site which was introduced at the $5^{\prime}$ and $3^{\prime}$ ends of the DNA for the subsequent cloning steps). The PCR-amplified AtNPR1 DNA was cloned into the pGEM-T plasmid. On the other hand, the ubiquitin promoter and nos terminator DNA sequences were amplified with primers UBI5', 5'-GCGAGCTCCTGCAGTGCAGCGTGACCCGG TCGTGC-3' and NOS3', 5'-gcgagctccegatctagtaacatagat-3' containing the $S a c$ I cloning site and cloned into the pGEM-T plasmid to obtain the pGEMT:ubi:nos plasmid. The AtNPR1 cDNA fragment was then inserted into the BamHI site of the pGEMT:ubi:nos plasmid under the control of the maize ubiquitin 1 promoter (ubil) and the nos terminator. Finally, the entire DNA fragment containing the $35 S C a M V$ promoter, AtNPRl cDNA, and terminator was cloned into the SacI-digested pCAMBIA1300 vector to obtain the pCAMBIA-ubil:: AtNPR1:: nos construct. The nucleotide sequence of the plant expression vector was verified by nucleotide sequencing. The parent pCAMBIA 1301 vector already contains the hygromycin phospho transferase ( $h$ ptII) gene encoding hygromycin resistance in the T-DNA region.

\section{RNA isolation and Northern blots.}

Total RNA was isolated from leaves collected from soilgrown plants at the two to three-leaf stage using TRIzol reagent (Invitrogen Corp., Carlsbad, CA, U.S.A.). RNAs were subjected to formaldehyde-containing agarose gel electrophoresis and transferred to nylon membranes (Hybond-N, Amersham, Chalfont, Buckinghamshire, U.K.). The DNA fragment coding for the AtNPRl gene was used as probe. Hybridizations were conducted at $42^{\circ} \mathrm{C}$ with the addition of $40 \%$ formamide in the hybridization solution.

\section{RT-PCR analysis.}

For RT-PCR of the rice defense genes, total RNA was extracted from leaves of rice plants at the three- to four-leaf stage at different times after fungal inoculation $(3,6,12$, and $24 \mathrm{~h}$ after inoculation with fungal spores). For each timepoint, leaves were collected from eight individual plants. The first cDNA was synthesized with DNase-treated total RNA (1 $\mu \mathrm{g}$ ) with Moloney murine leukemia virus (M-MLV) reverse transcriptase (Roche, Mannheim, Germany). Aliquots of the resulting RT reaction product were used as template for RTPCR analysis. Primers used for amplification reactions were for $O s P R-1 b$ (forward, 5'-CTTGGCGAGAACCTCTTCTG3'; reverse, 5'-GCCGGCTTATAGTTGCATGT-3'), TLP (PR5) (forward, 5'-CAGTACTGCTGCACCGGCTC-3'; reverse, 5'ACATCGATCAGATGCCAGCTAA-3'), PBZ1 (forward, 5'-C CGGGCACCATCTACACC-3'; reverse, 5'-CCTCGATCAT CT TGAGCATGC-3'), OsPR10 (forward, 5'-TCAGGCAG TTCAACTTCACCTC-3'; reverse, 5'-CTTAGCCTTGGTGA TCTCGTCC-3'), saltT (forward, 5'-GGAAATTTAAGCGAC CACGA-3'; reverse, 5'-GTCTTGCAGTGGAATGCTGA-3'), rab21 (forward, 5'-GGAATCCATTCAGTGCCAAT-3'; reverse, 5'-TTGATCCCCTTCTTCCTCCT-3'), dipl (forward, 5'-GGCTTTAGCTGAATCCATCG-3'; reverse, 5'-CTCCTT GAGCCCCTTCTTCT-3'), tIF5A (forward, 5'-GAGGAGCA CCATTTCGAGTC-3'; reverse, 5'-ACATCACAGTTGTGGG ACGA-3'), salt-stress-induced protein (forward, 5'-CACCC AAGAAGCTGTTAGGC-3'; reverse, 5'-GTCTTGCAGTGG AATGCTGA-3'), OsPRIOA (forward, 5'-GGTGTGGGAAG 
CACATACAA-3'; reverse, 5'-AGTAGCCATCCACGATGTC C-3'), and OsRDRl (forward, 5'-GCTACGTCCAACCATCA CCT-3'; reverse, 5'-TCATGTCCTGAAGCAGAACG-3'). The control of the rice Actin 1 gene was performed using the forward primer 5'-CCTCTTCCAGCCTTCCTTCATA-3'; reverse 5'-GCAATGCCAGGGAACATAGTG-3'. Three independent RT-PCR reactions for the three independent AtNPRI lines were carried out. RT-PCR products were quantified using a phosphorimager and the Quantity One software (Bio Rad, Munchen, Germany) and normalized according to Actin1.

\section{Phylogenetic analysis.}

The phylogenetic tree was obtained by the Neighbor-joining method (Saitou and Nei 1987). The tree was displayed with MEGA 3.1 program (Kumar et al. 2004) showing bootstrap values (from 1,000 replicates) higher than $50 \%$.

\section{Microscopic analyses.}

Microscopic analysis of leaves from transgenic and wildtype plants by bright-field and fluorescence microscopy was carried out as previously described (Dietrich et al. 1994). Cell autofluorescence was viewed by fluorescent microscopy (excitation filter 365, dichroic mirror $395 \mathrm{~nm}$, barrier filter $420 \mathrm{~nm}$ ) (Zeiss Axiophot microscope; Carl Zeiss, Thornwood, NY, U.S.A). For histochemical detection of superoxide $\mathrm{O}_{2}^{-}$, leaf sections of approximately $2 \mathrm{~cm}$ in length were excised from either transgenic or wild-type plants and stained as described by Fitzgerald and associates (2004).

\section{Disease resistance assays}

\section{with fungal and bacterial pathogens.}

Resistance of NPR1 rice plants to infection by the rice blast fungus $M$. oryzae (PR9 isolate, CIRAD collection, Montpellier, France) was assayed as previously described (Coca et al. 2004). The rice cv. Senia used for transformation in this work is highly susceptible to infection by the M. oryzae PR9 isolate (Coca et al. 2004). Blast resistance was also measured by counting the number of spores from wild-type and transgenic lines and by estimating the leaf area covered with lesions (Coca et al. 2006). The $F$. verticillioides isolate used in this work was collected from rice plants in Spain and supplied by the Facility of Plant Protection from the Generalitat de Catalunya. Evaluation of resistance to $F$. verticillioides and to $E$. chrysanthemi A3937 was carried out as described by GómezAriza and associates (2007). For each line, germination was scored at day 6 after inoculation with $F$. verticillioides spores relative to that of noninoculated plants. Root length of $E$. chrysanthemi-infected seedlings from wild-type and transgenic plants was determined and compared with that of noninfected seedlings using the Image $\mathbf{J}$ software. Infections were carried out three times (60 plants per line).

\section{Plant inoculation with RYMV \\ and enzyme-linked immunosorbent assay.}

Transgenic and wild-type plants (70 plants per line) were grown under controlled conditions in a biosafety level 2 greenhouse (IRD, Montpellier, France). Fifteen-day-old homozygous T2 plants were inoculated with RYMV particles diluted in phosphate buffer $\left(20 \mathrm{mM} \mathrm{KH}{ }_{2} \mathrm{PO}_{4}\right.$ and $\mathrm{K}_{2} \mathrm{HPO}_{4}$, pH 7.2; 50 $\mu \mathrm{g} / \mathrm{ml}$ ) by finger rubbing the leaves in the presence of Carborundum (Kouassi et al. 2006). Thirty plants of the same lines were mock inoculated with RYMV and grown under the same experimental conditions. Resistance to RYMV infection of AtNPRI plants was compared with that of two $O$. sativa indica cultivars, IR64 and Gigante, and two $O$. sativa japonica cultivars, Azucena and Nipponbare. Contrary to what is found in most of the indica cultivars which are very susceptible to RYMV, the Gigante indica cultivar shows a high degree of resistance to RYMV (Albar et al. 2006). On the other hand, the indica cv. IR64 is highly susceptible to RYMV. The two japonica cultivars used in this work, Azucena and Nipponbare, are partially resistant and partially tolerant, respectively, to RYMV.

Symptom severity at $28 \mathrm{dpi}$ was evaluated following the 1to-9 scale developed by the International Rice Research Institute (Los Banos, Philippines) SES. Typical responses of rice plants to RYMV are as follows: symptom scale 1 = no symptoms observed, a response typical of the highly resistant cv. Gigante; symptom scales 2 and 3 = sparse chlorotic spots or streaking on green leaves, seen in plants such as cv. Azucena; symptom scale $5=$ plant exhibiting pale green leaves with mottling, seen in plants such as Senia and Nipponbare; and symptom scales 7 to $9=$ yellow to orange leaves, typical of the highly susceptible cv. IR64. Analysis of variance and the Tukey's multiple comparisons test were used to compare susceptibility of rice plants to RYMV using XLSTAT software (Addinsoft, Brooklyn, NY, U.S.A.).

The level of virus accumulation was determined at different days postinoculation measured in locally inoculated leaves ( 7 dpi) and systemically infected leaves $(10,14$, and 21 dpi) by enzyme-linked immunosorbent assay analyses using an antibody against RYMV coat protein (N'Guessan et al. 2000). Leaves from 10 inoculated plants for each line were pooled and the virus content determined. Extracts were prepared using $0.05 \mathrm{M} \mathrm{Na}$ phosphate, $\mathrm{pH} 7.5$, and $0.15 \mathrm{M} \mathrm{NaCl}$ containing $0.1 \%$ Tween-20 as the extraction buffer.

\section{Abiotic and chemical treatment of plants.}

Wild-type (84 plants) and transgenic lines (four independent $\mathrm{T} 2$ homozygous lines and 72 plants per line) were grown under greenhouse conditions for 2 weeks. For salt-stress treatment, plants were transferred to flat trays containing $\mathrm{NaCl}$ for up to 5 days. Plants were then irrigated with water for 15 days. Each plant was grown in the same amount of soil and watered with the same volume of water. Salt treatments were also performed with in-vitro-grown rice seedlings. For this, seed from wild-type and transgenic lines (80 plants per line) were pregerminated in Murashige-Skoog medium containing gelrite at $0.85 \mathrm{~g} /$ liter and then treated with either $\mathrm{NaCl}(50,100,150$, or $200 \mathrm{mM})$, mannitol $(300 \mathrm{mM})$, or sterile water for 5 days.

Drought stress was induced by withholding water for up to 9 days. Plants were then irrigated normally for 15 days. Drought and salt tolerance were evaluated by determining the percentage of surviving plants after the period of recovery. Experiments to determine tolerance to salt and drought stresses were repeated four times and at different times of the year. Statistical analysis of data obtained in these experiments was performed using the $\chi^{2}$ test at a $5 \%$ confidence level.

For treatment with SA, 2-week-old plants were sprayed with a solution of $2 \mathrm{mM} \mathrm{SA}$. Control plants were treated with water. Plants were collected at $24 \mathrm{~h}$ after the onset of treatment.

\section{ACKNOWLEDGMENTS}

J. Quilis was a recipient of a predoctoral fellowship from the Generalitat de Catalunya. We thank X. Dong (Duke University, Durham, NC, U.S.A.) for the Arabidopsis AtNPR1 cDNA. We are also thankful to J. J. López-Moya for critical reading of the manuscript and to Nazaire Kouassi for help and technical assistance for experiments with RYMV. This work was supported by grants from the Ministerio de Ciencia y Tecnología, BIO2003-04936-CO2-01 and BIO2006-05583 to B. S. Segundo and BIO2003-04936-CO2-02 to J. Messeguer. We also thank the Xarxa de Referència en Biotecnologia for substantial support. 


\section{LITERATURE CITED}

Agrawal, G. K., Rakwal, R., Jwa, N.-S., and Agrawal, V. P. 2001. Signalling molecules and blast pathogen attack activates rice OsPRla and OsPR $1 b$ genes: A model illustrating components participating during defense/stress response. Plant Physiol. Biochem. 39:1095-103.

Albar, L., Lorieux, M., Ahmadi, N., Rimbault, I., Pinel, A., Sy, A. A., Fargette, D., and Ghesquière, A. 1998. Genetic basis and mapping of the resistance to rice yellow mottle virus. I. QTLs identification and relationship between resistance and plant morphology. Theor. Appl. Genet. 97:1145-1154.

Albar, L., Bangratz-Reyser, M., Hébrard, E., Ndjiondjop, M.-N., Jones, M., and Ghesquière, A. 2006. Mutations in the eIF(iso)4G translation initiation factor confer high resistance of rice to Rice yellow mottle virus. Plant J. 47:417-426.

Bakker, W. 1974. Characterization and ecological aspects of rice yellow mottle virus in Kenya. Agric. Res. Rep. (Wageningen) 829:1-152.

Baulcombe, D. 2004. RNA silencing in plants. Nature 431:356-363.

Cao, H., Bowling, S. A., Gordon, A. S., and Dong, X. 1994. Characterization of an Arabidopsis mutant that is nonresponsive to inducers of systemic acquired resistance Plant Cell 6:1583-1592.

Cao, H., Glazebrook, J., Clarke, J. D., Volko, S., and Dong, X. 1997. The Arabidopsis NPR1 gene that controls systemic acquired resistance encodes a novel protein containing ankyrin repeats. Cell 88:57-63.

Cao, H., Li, X., and Dong, X. 1998. Generation of broad-spectrum disease resistance by overexpression of an essential regulatory gene in systemic acquired resistance. Proc. Natl. Acad. Sci. U.S.A. 95:6531-6536.

Chern, M. S., Fitzgerald, H. A., Yadav, R. C., Canlas, P. E., Dong, X., and Ronald, P. C. 2001. Evidence for a disease-resistance pathway in rice similar to the NPR1-mediated signaling pathway in Arabidopsis. Plant J. 27:101-113.

Chern, M. S., Fitzgerald, H. A., Canlas, P. E., Navarre, D. A., and Ronald, P. C. 2005. Overexpression of a rice NPR1 homologue leads to constitutive activation of defense response and hypersensitivity to light. Mol. Plant-Microbe Interact. 18:511-520.

Claes, B., Dekeyser, R., Villarroel, R., Van den Bulcke, M., Bauw, G., Van Montagu, M., and Caplan, A. 1990. Characterization of a rice gene showing organ-specific expression in response to salt stress and drought. Plant Cell 2:19-27.

Coca, M., Bortolotti, C., Rufat, M., Peñas, G., Eritja, R., Tharreau, D., Martinez del Pozo, A., Messeguer, J., and San Segundo, B. 2004. Transgenic rice plants expressing the antifungal AFP protein from Aspergillus giganteus show enhanced resistance to the rice blast fungus Magnaporthe grisea. Plant Mol. Biol. 54:245-259.

Coca, M., Peñas, G., Gómez, J., Campo, S., Bortolotti, C., Messeguer, J., and San Segundo, B. 2006. Enhanced resistance to the rice blast fungus Magnaporthe grisea conferred by expression of a cecropin A gene in transgenic rice. Planta 223:392-406.

Conrath, U., Bechers, G. J. M., Flors, V., García-Agustín, P., Jakab, G., Mauch, F., Newman, M.-A., Pieterse, C. M. J., Poinssot, B., Pozo, M. J., Pugin, A., Schaffrath, U., Ton, J., Wendehenne, D., Zimmerli, L., and Mauch-Mani, B. 2006. Priming: Getting ready for battle. Mol. PlantMicrobe Interact. 19:1062-1071.

Dalmay, T., Hamilton, A., Rudd, S., Angell, S., and Baulcombe, D. C. 2000. An RNA-dependent RNA polymerase gene in Arabidopsis is required for posttranscriptional gene silencing mediated by a transgene but not by a virus. Cell 101:543-553.

Dean, R. A., Talbot, N. J., Ebbole, D. J., Farman, M. L., Mitchell, T. K., Orbach, M. J., Thon, M., Kulkarni, R., Xu, J. R., Pan, H., Read, N. D., Lee, Y. H., Carbone, I., Brown. D., Oh, Y. Y., Donofrio, N., Jeong, J. S., Soanes, D. M., Djonovic, S., Kolomiets, E., Rehmeyer, C., Li, W., Harding, M., Kim, S., Lebrun, M. H., Bohnert, H., Coughlan, S., Butler, J., Calvo, S., Ma, L. J., Nicol, R., Purcell, S., Nusbaum, C., Galagan, J. E., and Birren, B. W. 2005. The genome sequence of the rice blast fungus Magnaporthe oryzae. Nature 434:980-986.

Delaney, T. P., Friedrich, L., and Ryals, J. A. 1995. Arabidopsis signal transduction mutant defective in chemically and biologically induced disease resistance. Proc. Natl. Acad. Sci. U.S.A. 92:6602-6606.

Dempsey, D. A, Shah, J., and Klessig, D. F. 1999. Salicylic acid and disease resistance in plants. Crit. Rev. Plant Sci. 18:547-575.

Despres, C., DeLong, C., Glaze, S., Liu, E., and Fobert, P. R. 2000. The Arabidopsis NPR1/NIM1 protein enhances the DNA binding activity of a subgroup of the TGA family of bZIP transcription factors. Plant Cell 12:279-290.

Dietrich, R. A., Delaney, T.-P., Uknes, S. J., Ward, E. R., Ryals, J. A., and Dangl, J. L. 1994. Arabidopsis mutants simulating disease resistance response. Cell 77:565-577.

Fargette, D., Pinel, A., Abubakar, Z., Traore, O., Brugidou, C., Fatogoma, S., Hebrard, E., Choisy, M., Sere, Y., Fauquet, C., and Konate, G. 2004. Inferring the evolutionary history of rice yellow mottle virus from ge- nomic, phylogenetic, and phylogeographic studies. J Virol. 78:32523261.

Fitzgerald, H. A., Chern, M.-S., Navarre, R., and Ronald, P. C. 2004 Overexpression of (At)NPR1 in rice leads to a BTH- and environmentinduced lesion-mimic/cell death phenotype. Mol. Plant-Microbe Interact. 17:140-151.

Friedrich, L., Lawton, K., Dietrich, R., Willits, M., Cade, R., and Ryals, J. 2001. NIM1 overexpression in Arabidopsis potentiates plant disease resistance and results in enhanced effectiveness of fungicides. Mol. PlantMicrobe Interact. 14:1114-1124.

Glazebrook, J. 2005. Contrasting mechanisms of defense against biotrophic and necrotrophic pathogens. Annu. Rev. Phytopathol. 43:205-227.

Glazebrook, J., Rogers, E. E., and Ausubel, F. M. 1996. Isolation of Arabidopsis mutants with enhanced disease susceptibility by direct screening. Genetics 143:973-982.

Gómez-Ariza, J., Campo, S., Rufat, M., Estopà, M., Messeguer, J., San Segundo, B., and Coca, M. 2007. Sucrose-mediated potentiation of plant defense responses and broad spectrum disease resistance by overexpression of the maize pathogenesis-related PRms protein in rice plants. Mol. Plant-Microbe Interact. 20:832-842.

Goto, M. 1979. Dissemination of Erwinia chrysanthemi, the causal organism of bacterial foot rot of rice. Plant Dis. Rep. 63:100-103.

Hammond-Kosack, K. E., and Parker, J. 2003. Deciphering plant-pathogen communication: Fresh perspectives for molecular resistance breeding. Curr. Opin. Biotechnol. 14:177-193.

Heidel, A. J., and Dong, X. 2006. Fitness benefits of systemic acquired resistance during Hyaloperonospora parasitica infection in Arabidopsis thaliana. Genetics 173:1621-1628.

Heidel, A. J., Clarke, J. D., Antonovics, J., and Dong, X. 2004. Fitness costs of mutations affecting the systemic acquired resistance pathway in Arabidopsis thaliana. Genetics 168:2197-2206.

Kachroo, P., Yoshioka, K., Shah, J., Dooner, H. K., and Klessig, D. F. 2000. Resistance to Turnip Crinkle Virus in Arabidopsis is regulated by two host genes and is salicylic acid dependent but NPR1, ethylene, and jasmonate independent. Plant Cell 12:677-690.

Kouassi, N. K., Chen, L., Siré, C., Bangratz-Reyser, M., Beachy, R. N., Fauquet, C. M., and Brugidou, C. 2006. Expression of Rice yellow mottle virus coat protein enhances virus infection in transgenic plants. Arch Virol. 151:2111-2122.

Kinkema, M., Fan, W., and Dong, X. 2000. Nuclear localization of NPR1 is required for activation of gene expression. Plant Cell 12:2339-2350.

Kumar, S., Tamura, K., and Nei, M. 2004. MEGA3: Integrated software for molecular evolutionary genetics analysis and sequence alignment. Brief. Bioinform. 5:150-163.

Lin, W.-C., Lu, Ch.-F., Wu, J.-W., Cheng, M.-L., Lin, Y.-M., Yang, N.-S., Black, L., Green, S. K., Wang, J.-F., and Cheng, C.-P. 2004. Transgenic tomato plants expressing the Arabidopsis NPR1 gene display enhanced resistance to a spectrum of fungal and bacterial diseases. Transgenic Res. 13:567-581.

Liu, Y., Schiff, M., Marathe, R., and Dinesh-Kumar, S. P. 2002. Tobacco Rar1, EDS1 and NPR1/NIM1 like genes are required for N-mediated resistance to Tobacco mosaic virus. Plant J. 30:415-429.

Makandar, R., Essig, J. S., Schapaugh, M. A., Trick, H. N., and Shah, J. 2006. Genetically engineered resistance to Fusarium head blight in wheat by expression of Arabidopsis NPR1. Mol. Plant-Microbe Interact. 19:123-129.

Malnoy, M., Jin, Q., Borejsza, E. E., He, S. Y., and Aldwinckle, H. S. 2007. Overexpression of the apple $M p N P R 1$ gene confers increased disease resistance in Malus $\times$ domestica. Mol. Plant-Microbe Interact. 20:1568-1580.

Midoh, N., and Iwata, M. 1996. Cloning and characterization of a probenazole-inducible gene for an intracellular pathogenesis-related protein in rice. Plant Cell Physiol. 37:9-18.

Mou, Z., Fan, W., and Dong, X. 2003. Inducers of plant systemic acquired resistance regulate NPR1 function through redox changes. Cell 113:935-944.

Mourrain, P., Beclin, C., Elmayan, T, Feuerbach, F., Godon, C., Morel, J. B., Jouette, D., Lacombe, A. M., Nikic, S., Picault, N., Remoue, K., Sanial, M., Vo, T. A., and Vaucheret, H. 2000. Arabidopsis SGS2 and SGS3 genes are required for posttranscriptional gene silencing and natural virus resistance. Cell 101:533-542.

Ndjiondjop, M. N., Albar, L., Fargette, D., Fauquet, C., and Ghesquière, A. 1999. The genetic basis of high resistance to Rice yellow mottle virus (RYMV) in cultivars of two cultivated rice species. Plant Dis. 83:931935.

Nelson, P. E. A. E., Desjardins, A. E., and Plattner, R. D. 1993. Fumonisins, mycotoxins produced by Fusarium species: Biology, chemistry, and significance. Annu. Rev. Phytopathol. 31:233-252.

N'Guessan, P. N., Pinel, A., Caruana, M. L., Frutos, R., Sy, A., Guesquière, A., and Fargette, D. 2000. Evidence of the presence of two 
serotypes of rice yellow mottle sobemovirus in Côte d'Ivore. Eur. J. Plant Pathol. 106:167-178.

Oh, S.-J., Song, S. I., Kim Y. S., Jang, H.-J., Kim, S. Y., Kim, M., Kim Y.K, Nahm, B. H., and Kim, J.-K. 2005. Arabidopsis CBF3/DREB1A and $\mathrm{ABF} 3$ in transgenic rice increased tolerance to abiotic stress without stunting growth. Plant Physiol. 138:341-351.

Pons, M. J., Marfà, V., Melé, E., and Messeguer, J. 2000. Regeneration and genetic transformation of Spanish rice cultivars using mature embryos. Euphytica 114:117-122.

Rabbani, M. A., Maruyama, K., Abe, H., Ayub Khan, M., Katsura, K., Ito, Y., Yoshiwara, K., Seki, M., Shinozaki, K., and Yamaguchi-Shinozaki, K. 2003. Monitoring expression profiles of rice genes under cold, drought, and high-salinity stresses and abscisic acid application using cDNA microarray and RNA gel-blot analyses. Plant Physiol. 133:1755-1767.

Rao, M. V., Lee, H., and Davis, K. R. 2002. Ozone-induced ethylene production is dependent on salicylic acid, and both salicylic acid and ethylene act in concert to regulate ozone-induced cell death. Plant J. 32:447456.

Rochon, A., Boyle, P., Wignes, T., Fobert, P., and Després, C. 2006. The coactivator function of Arabidopsis NPR1 requires the core of its $\mathrm{BTB} / \mathrm{POZ}$ domain and the oxidation of C-terminal cysteines. Plant Cell 18:3670-3685.

Ryals, J. A., Neuenschwander, U. H., Willits, M. G., Molina, A., Steiner, H.-Y., and Hunt, M. D. 1996. Systemic acquired resistance. Plant Cell 8:1809-1819.

Ryals, J., Weymann, K., Lawton, K., Friedrich, L., Ellis, D., Steiner, H.-Y., Johnson, J., Delaney, T. P., Jesse, T., Vos, P., and Uknes, K. 1997. The Arabidopsis NIM1 protein shows homology to the mammalian transcription factor inhibitor I kappa B. Plant Cell 9:425-439.

Saitou, N., and Nei, M. 1987. The Neighbouring-joining method: A new method for reconstruction of phylogenetic tress. Mol. Biol. 4:406-425.

Seki, M., Kamei, A., Yamaguchi-Shinozaki, K., and Shinozaki, K. 2003. Molecular responses to drought, salinity and frost: Common and different paths for plant protection. Curr. Opin. Biotechnol. 14:194-199.

Shah, J., Tsui, F., and Klessig, D. F. 1997. Characterization of a salicylic acid-insensitive mutant (sai1) of Arabidopsis thaliana, identified in a selective screen utilizing SA-inducible expression of the tms 2 gene. Mol. Plant-Microbe Interact. 10:69-78.

Shimono, M., Sugano, S., Nakayama, A., Jiang, C-J., Ono, K, Toki, S., and Takatsuki, H. 2007. Rice WRKY45 plays a crucial role in benzothiadiazole-inducible blast resistance. Plant Cell 19:2064-2076.

Talbot, N. J. 2003. On the trail of a cereal killer: Exploring the biology of Magnaporthe grisea. Annu. Rev. Microbiol. 57:177-202.

Thottappilly, G., and Rossell, H. W. 1993. Evaluation of resistance to Rice Yellow mottle virus in Oryza species. Indian J. Virol. 9:65-73.

van Loon, L. C., Rep, M., and Pieterse, C. M. J. 2006. Significance of inducible defense-related proteins in infected plants. Annu. Rev. Phytopathol. 44:135-162.

Velazhahan, R., Chen-Cole, K., Anuratha, C. S., and Muthukrishnan, S. 1998. Induction of thaumatin-like proteins (TLPs) in Rhizoctonia solani-infected rice and characterization of two new cDNA clones. Physiol. Plant. 102:21-28.

Ventelon-Debout, M., Delalande, F., Brizard, J.-P., Diemer, H., van Dorsselaer, A., and Brugidou, C. 2004. Proteome analysis of cultivar- specific deregulations of Oryza sativa indica and $O$. sativa japonica cellular suspensions undergoing Rice yellow mottle virus infection. Proteomics 4:216-225.

Wang, D., Weaver, N. D., Kesarwani, M., and Dong, X. 2005. Induction of protein secretory pathway is required for systemic acquired resistance. Science 308:1036-1040.

Ward, E. R., Uknes, S. J., Williams S. C., Dincher, S. S., Wiederhold, D. L., Alexander, D. C., Ahl-Goy, P., Métraux J.-P., and Ryals J. A. 1991. Coordinate gene activity in response to agents that induce systemic acquired resistance. Plant Cell 3:1085-1094.

Wassenegger, M., and Krczal, G. 2006. Nomenclature and functions of RNA-directed RNA polymerases. Trends Plant Sci. 11:142-151.

Xie, Z., Fan, B., Chen, C., and Chen, Z. 2001. An important role of an inducible RNA-dependent RNA polymerase in plant antiviral defense. Proc. Natl. Acad. Sci. U.S.A. 98:6516-6521.

Xiong, L., and Yang, Y. 2003. Disease resistance and abiotic stress-tolerance in rice are inversely modulated by an abscisic-acid-inducible mitogen-activated protein kinase. Plant Cell 15:745-759.

Yang, S-J., Carter, S. A., Cole, A. B., Cheng, N.-H., and Nelson, R. S. 2004. A natural variant of a host RNA-dependent RNA polymerase is associated with increased susceptibility to viruses by Nicotiana benthamiana. Proc Natl. Acad. Sci. U.S.A. 101:6297-6302.

Yu, D., Fan, B., MacFarlane, S. A., and Chen, Z. 2003. Analysis of the involvement of an inducible Arabidopsis RNA-dependent RNA polymerase in antiviral defense. Mol. Plant-Microbe Interact. 16:206-216.

Yuan, Y., Zhong, S., Li, Q., Zhu, Z., Lou, Y., Wang, L., Wang, J., Wang, M., Li, Q., Yang, D., and He, Z. 2007. Functional analysis of rice NPR1-like genes reveals that OsNPR1/NH1 is the rice orthologue conferring disease resistance with enhanced herbivore susceptibility. Plant Biotechnol. J. 5:313-324.

Zhang, Y, Fan, W., Kinkema, M., Li, Z., and Dong, X. 1999. Interaction of NPR1 with basic leucine zipper protein transcription factors that bind sequences required for salicylic acid induction of the PR-1 gene. Proc. Natl. Acad. Sci. U.S.A. 96:6523-6528.

Zhang, Y., Tessaro, M. J., Lassner, M., and Li, X. 2003. Knockout analysis of Arabidopsis transcription factors TGA2, TGA5, and TGA6 reveals their redundant and essential roles in systemic acquired resistance. Plant Cell 15:2647-2653.

Zhou, J.-M., Trifa, Y., Silva, H., Pontier, D., Lam, E., Shah, J., and Klessig, D. 2000. NPR1 differentially interacts with members of the TGA-OBF family of transcription factors that bind an element of the PR-1 gene required for induction by salicylic acid. Mol. Plant-Microbe Interact. 13:191-200.

Zhu, J. K. 2002. Salt and drought stress signal transduction in plants. Annu. Rev. Plant Biol. 53:247-272.

\section{AUTHOR-RECOMMENDED INTERNET RESOURCES}

International Rice Research Institute Standar Evaluation System for Rice (SES): www.knowledgebank.irri.org/ses/SES.htm Invitrogen website: www.invitrogen.com

National Center for Biotechnology Information: www.ncbi.nlm.nih.gov National Institute of Health Image J software: rsb.info.nih.gov/ij 